UCRL-JC-113794

PREPRINT

\title{
Superplasticity in Ceramic and Metal Matrix Composites and the Role of Grain Size, Segregation, Interfaces, and Second Phase Morphology
}

\author{
J. Wadsworth \\ T.G. Nieh
}

This paper was prepared for submittal to the Grain Boundary and Interface Phenomena Workshop

Berkeley, CA

Octobert 16-21, 1992

October 1992

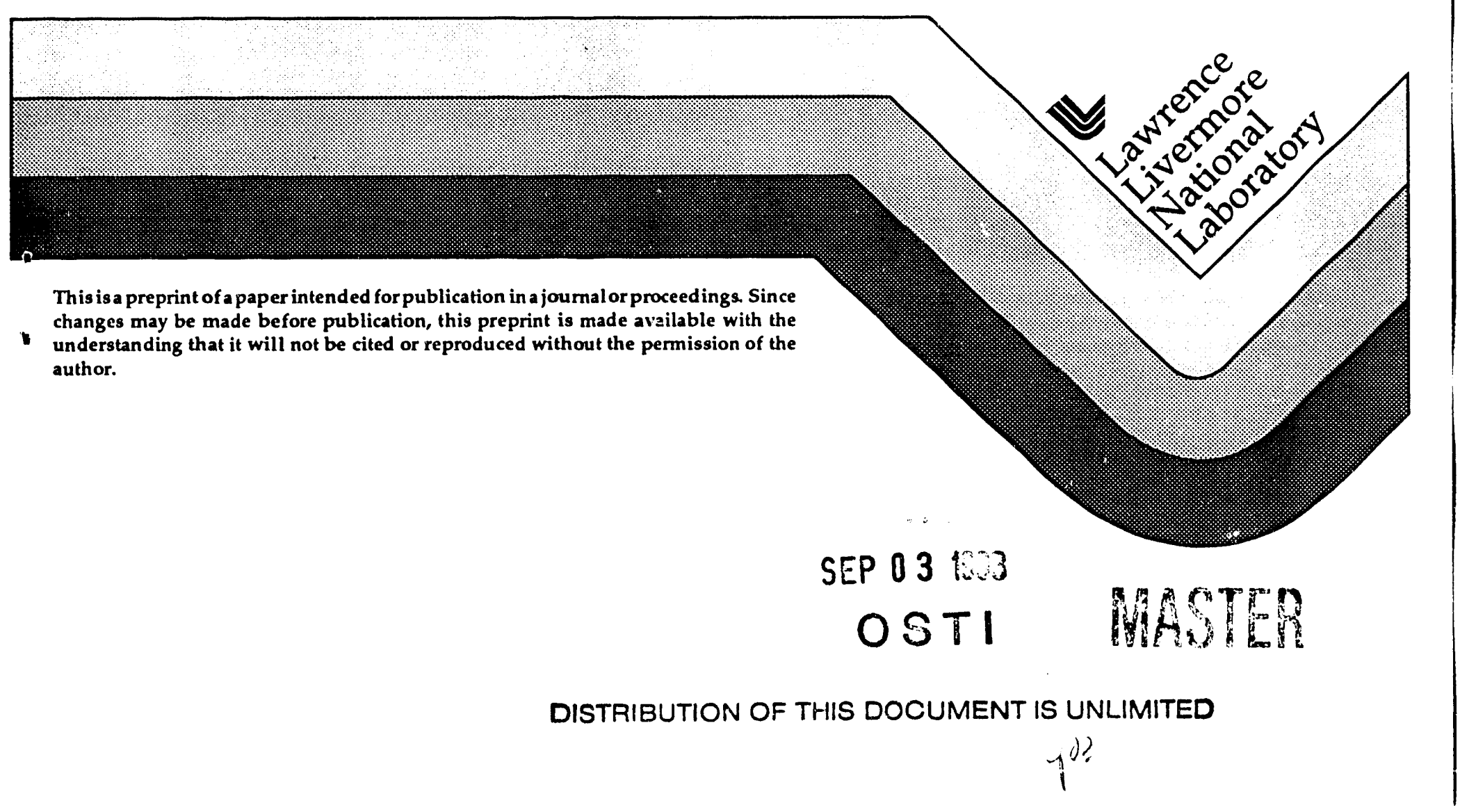




\section{DISCLAIMER}

This document was prepared as an account of work sponsored by an agency of the United States Government. Neither the United States Government nor the University of California nor any of their employees, makes any warranty, express or implied, or assumes any legal liability or responsibility for the accuracy, completeness, or usefulness of any information, apparatus, product, or process disclosed, or represents that its use would not infringe privately owned rights. Reference herein to any specific commercial products, process, or service by trade name, trademark, manufacturer, or otherwise, does not necessarily constitute or imply its endorsement, recommendation, or favoring by the United States Govemment or the University of California. 'The views and opinions of authors expressed herein do not necessarily state or reflect those of the United States Government or the University of California, and shall not be used for advertising or product endorsement purposes. 


\title{
Superplasticity in Ceramic a...d Metal Matrix Composites and the Role of Grain Size, Segregation, Interfaces, and Second Phase Morphology
}

\author{
J. Wadsworth and T.G. Nieh \\ Lawrence Livermore National Laboratory \\ Chemistry and Materials Science \\ P.O. Box 808, L-353 \\ Livermore, CA94550
}

This manuscript is a contribution to the DOE workshop, held at Berkeley, CA, October 16-21, 1992. Correspondance on the paper should be sent to J. Wadsworth at the above address:

Tel. (510)423-2184, Fax (510)423-7040

\begin{abstract}
Structural ceramics and ceramic composites have been shown to exhibit superplasticity in recent times and this discovery has attracted tremendous interest. Although the number of ceramics that have been found to exhibit superplasticity is now quite large, there are considerable gaps in the understanding of the detailed requirements for superplasticity in ceramics. Additionally, superplastic behavior at very high strain rates $\left(1 \mathrm{~s}^{-1}\right)$ in metallic-based materials is an area of increasing research. In this case, the phenomenon has been observed quite extensively in aluminum alloy-based metal matrix composites and mechanically alloyed aluminum- and nickel-based materials. Again, the details of the structural requirements of this phenomenon are not yet understood. In the present paper, experimental results on superplasticity in ceramic-based materials and on high strain rate behavior in metallic-based materials are presented. The roles of grain size, grain boundary and interface chemistry, and second phase morphology' and compatibility with the matrix material will be emphasized.
\end{abstract}




\section{INTRODUCTION}

A recent review of the 1991 superplasticity conference, held in Osaka, has been presented by Langdon and Wadsworth [1]. In the review, it was clear that in recent times major areas of research interest in superplasticity include not only conventional metallic alloys, but also ceramics, ceramic composites, intermetallics, metal matrix composites, and mechanically alloyed materials. In the latter two groups, i.e., metal matrix composites and mechanically alloyed materials, superplasticity is found at high strain rates that approach conventional metal forming rates such as forging.

One conclusion in the above reviews was that simple descriptions of the key characteristics of superplastic materials must be changed [1]. The prior definitions of superplastic materials were essentially centered on a "metallic two-phase material with a uniform, fine, equiaxed, grain (phase) size." Clearly, the materials that have now been shown to exhibit superplasticity are far more broad than would be covered by this definition. A more appropriate description, as presented in the above review, was "Metallic, ceramic, composite, or intermetallic multiphase materials, with uniform or non-uniform, relatively coarse $(20 \mu \mathrm{m})$ to ultrafine $(30 \mathrm{~nm})$ grain size, that have isotropic or anisotropic grain (phase) shape, size, or orientation."

The purpose of this paper is to document some of the experimental details of the new observations of superplasticity in ceramic-based materials and high strain rate superplasticity in metal matrix composites and mechanically alloyed materials. In this regard, the effects of grain size, grain boundary and interface chemistry, as well as second phase morphology and compatibility with the matrix material will be discussed.

\section{DISCUSSION}

\section{Overview}

Grain boundary sliding is generally believed to be the dominant deformation mode in finegrained, superplastic alloys. In the case of grain boundary sliding, grain size is certainly the most dominant microstructural parameter.

Grain size has not only a dominant effect on the superplasticity of metals, but also on ceramics. To highlight the effect of grain size on the deformation behavior of ceramics, Fig. 1 shows the modulus-compensated flow stresses measured from a number of studies on tetragonal zirconias as a function of diffusivity-compensated strain rate. It is apparent that for a given stress that the strain rate increases dramatically as grain size decreases. (Or, conversely, that for a given imposed strain rate the stress required decreases dramatically as grain size decreases.) Figure 1 illustrates the importance of grain boundary sliding mechanisms in fine-grained ceramics. In the remainder of this paper, key observations relating the effects of interfaces to superplastic behavior from these two areas, i.e. superplastic ceramics and high strain rate superplasticity will be reviewed. 
An overview of the superplastic behavior of metal alloys, and in particular Al alloys, to demonstrate the overwhelming effect of grain size is given in Fig. 2. In this figure, the elongationto-failure is shown as a function of strain rate for (i) $7475 \mathrm{Al}$, (ii) a USSR alloy V96Ts that is rather similar in composition to the 7000 series alloy (but contains $\mathrm{Zr}$ as a grain refining element instead of Cr), (iii) Al-Li 2090 alloy, (iv) the commercial SUPRAL alloys, (v) $\mathrm{SiC}_{\mathrm{w}} / \mathrm{Al}$ and $\mathrm{Si}_{3} \mathrm{~N}_{4(\mathrm{w})} / \mathrm{Al}$ composites, (vi) a $\mathrm{Zr}$-modified $\mathrm{Al} 2124$, and (vii) mechanically-alloyed $\mathrm{Al} 9021$. The grain size ranges of these alloy groups are 10-20 $\mu \mathrm{m}$ for the $7475 \mathrm{Al}$ alloys, about $5 \mu \mathrm{m}$ for the USSR alloy, 2 $3 \mu \mathrm{m}$ for the $2090 \mathrm{Al}$ and SUPRAL alloys, $1 \mu \mathrm{m}$ or less for the $\mathrm{SiC}_{\mathrm{w}} / \mathrm{Al}$ composites and $\mathrm{Zr}$ modified $\mathrm{Al} 2124$, and $0.5 \mu \mathrm{m}$ for $\mathrm{Al} 9021$. Figure 1 clearly illustrates a general trend; namely, there is an increased strain rate for optimal superplastic flow with a decrease in grain size.

\section{Superplastic Ceramics}

Since the first categorical demonstration of superplasticity in a crystalline ceramic in 1986, the area of superplastic ceramics has been the subject of considerable interest and reviev papers are now available [2-6]. As a result of these intensive efforts, many fine-grained polycrystalline ceramics have been demonstrated to be superplastic in tension. These include yttria-stabilized tetragonal zirconia polycrystal (Y-TZP) [7-9], Y-doped $\mathrm{Al}_{2} \mathrm{O}_{3}$ [10], Hydroxyapatite [11], $\beta$ spodumene glass ceramics [12,13], $\mathrm{Al}_{2} \mathrm{O}_{3}$-reinforced $\mathrm{Y}$-TZP $\left(\mathrm{Al}_{2} \mathrm{O}_{3} / \mathrm{YTZ}\right)$ [14-19], SiC-reinforced $\mathrm{Si}_{3} \mathrm{~N}_{4}\left(\mathrm{SiC}_{\mathrm{Si}} \mathrm{N}_{4}\right)$ [20,21], and iron-iron carbide $\left(\mathrm{Fe} / \mathrm{Fe}_{3} \mathrm{C}\right)$ [22] composites. The knowledge of fundamental issues gained from these studies has now advanced to the stage that the technological application of superplastic deformation is beginning to recieve increasing attention. Example includes successful biaxial gas-pressure deformation of a $20 \% \mathrm{Al}_{2} \mathrm{O}_{3} / \mathrm{YTZ}$ [23]. Taken together, these forming processes offer a technological advantage of greater dimensional control and a wider variety and complexity of shapes than is possible with conventional ceramic shaping technology. It is now possible to make intricate, net shaped, parts from superplastic YTZ sheet. Examples of a cone-on-cylinder geometry, a hat section, and a hemisphere are shown in Fig. 3. These articles were all formed at $1550^{\circ} \mathrm{C}$, using a forming pressure of $690 \mathrm{kPa}$, and required forming times from 20 - 90 minutes (depending upon the strain required). From Fig. 3, it is clear that the manufacturing technology to superplastically form net-shaped ceramic articles is now on the horizon.

The ceramic-base materials made superplastic to date are fine-grained materials. An example is the $3 \mathrm{~mol} \%$ yttria-stabilized tetragonal zirconia polycrystal (3Y-TZP). A micrograph from a $3 \mathrm{Y}$ TZP sample, with a grain size of about $0.2 \mu \mathrm{m}$, is shown in Fig. 4. Wakai et al. [7] first showed that this material was superplastic at $1450^{\circ} \mathrm{C}$ with $>120 \%$ elongation and a strain-rate-sensitivity exponent of 0.5. Subsequent studies by Nieh and Wadsworth [9] on this material have shown elongations of up to $800 \%$ in $3 \mathrm{Y}-\mathrm{TZP}$ and $625 \%$ in a ceramic composite of $3 \mathrm{Y}$ - $\mathrm{Y}$ TZ containing $20 \% \mathrm{Al}_{2} \mathrm{O}_{3}$ as shown in Fig. 5. Typical high strain rate sensitivity values of about $\mathrm{m}=0.3-0.5$ are found for the ceramics and ceramic composites. An example is given in Fig. 6 for the cor iposite 
material. As previously described, the deformation and fracture properties of a superplastic ceramic are quite sensitive to grain size. Examples are illustrated in Fig. 7 for the monolithic Y-TZP and an $\mathrm{Al}_{2} \mathrm{O}_{3} / \mathrm{Y}-\mathrm{TZP}$ composite. It is evident f:om both figures that the flow stress increases and elongation decreases as the grain size increases.

The grain sizes required for fine-grain superplasticity are typically about $10 \mu \mathrm{m}$ or less for metals, but about $1 \mu \mathrm{m}$ or less for ceramics. (As demonstrated above, in Fig. 7, the superplastic properties of a ceramic degrade rapidly when the grain size is over $1 \mu \mathrm{m}$.) However, because of the fineness of the grain structure, the microstructure of a superplastic ceramic is usually thermally unstable at high temperatures; as a result, grain growth can take place readily at superplastic deformation temperatures [24]. For example, static as well as dynamic grain growth have been observed during the superplastic deformation of $\mathrm{Y}-\mathrm{TZP}$ at temperatures above $1300^{\circ} \mathrm{C}$. Both static and dynamic grain growth were found to obey a similar equation of the form : $D^{n}-D_{o}{ }^{n}=k t$, where $D$ and $D_{o}$ are the instantaneous and initial grain sizes, respectively, $t$ is the annealing time, and $k$ is the kinetic constant for either static or dynamic grain growth. The $n$ value was found to be 3 , suggesting that grain growth in Y-TZP is controlled by solute or impurity drag, based on the model originally developed by Cahn [25] and advanced by Brook [26]. Grain boundary migration in YTZP is believed to be controlled by the diffusion of $Y$ atoms which segregate at grain boundaries. (Evidence of $\mathrm{Y}$ segregation at the grain boundaries of Y-TZP will be presented later.)

An area of controversy in these materials is whether or not there is a glassy phase at the grain boundaries and, if so, whether or not it plays an important role in the superplastic deformation process. In one study of these grain boundary structures of superplastic Y-TZP, high resolution electron microscopy was used. A representative high resolution lattice image of a grain boundary triple junction in Y-TZP is shown in Fig. 8. Lattice fringes from the three grains shown in Fig. 8 can be followed to their intersections at both the grain boundary interfaces and the triple junction, demonstrating the absence of any second phase. Energy dispersive spectroscopy (EDS) analysis of grain boundaries and triple junctions to detect silicon was unsuccessful. This is because the bulk $\mathrm{SiO}_{2}$ content of the superplastic Y-TZP is low $(0.002 \mathrm{wt} . \%)$, and the fact that, given the close proximity of the Si $\mathrm{K} \alpha(1.740 \mathrm{keV})$ and $\mathrm{Y} \mathrm{L} \mathrm{L}_{\alpha \mathrm{l}}(1.922 \mathrm{keV})$ lines, detection of small amounts of silicon in Y-TZPs using EDS is not straightforward.

To study further the chemical composition of grain boundaries, Nieh et al [27] also used Auger Electron Spectroscopy (AES) and X-ray Photoelectron Spectroscopy (XPS). The chemical composition on intergranular fracture surfaces was examined after superplastic deformation to determine if a low molting point amorphous phase containing either $\mathrm{Si}$ or $\mathrm{Na}$ was present. From AES it was determined that no $\mathrm{Na}(990 \mathrm{eV})$ is present at grain boundaries. Attempts to analyze for $\mathrm{Si}$ using AES were unsuccessful since peaks for both $\mathrm{Si}$ and $\mathrm{SiO}_{2}$ overlap with peaks from either $\mathrm{Y}$ or $\mathrm{Zr}$. As a result, XPS was subsequently carried out using an $\mathrm{Al} \mathrm{K} \alpha \mathrm{X}$-ray source. The $\mathrm{Zr} 3 \mathrm{~d}$ line 
$(182.2 \mathrm{eV})$ was used as a reference to correct for sample charging during analysis. The XPS spectrum from the fracture surface of a Y-TZP specimen, supeiplastically tested at $1650^{\circ} \mathrm{C}$ at a strain rate of $2.7 \times 10^{-4} \mathrm{~s}^{-1}$, is shown in Fig. 9. Four elements were detected; ZZ,Y,O, and C. The presence of carbon is a result of atomic adsorption and can readily be removed by argon ion sputtering. Neither $\mathrm{Na}(496 \mathrm{eV}), \mathrm{Si}(99.1$ and $149 \mathrm{eV})$, or $\mathrm{Fe}(710 \mathrm{eV})$ were detected as impurities at grain boundaries. Although an accurate quantitative evaluation of the chemical composition of grain boundaries in this Y-TZP is difficult, semi-quantitative estimates of grain boundary composition from XPS analysis are given in Table 1. For comparison purposes, the bulk chemical composition of the ceramic is also included in the Table. The $\mathrm{Y} / \mathrm{Zr}$ peak ratio at grain boundaries was noted to be about 1.6 times that of grain interiors, indicating that $Y$ segregates to grain boundaries in Y-TZPs. Hwang and Chen [28] recently proposed that the grain boundaries of zirconia were positively charged. As a result, any divalent and trivalent cations are expected to be enriched at the grain boundary and to thereby decrease the grain boundary mobility. This offers an explanation for the observed grain growth behavior of Y-TZP, discussed earlier. The effect of this $\mathrm{Y}$ segregation on the superplastic flow behavior of Y-TZP is, however, not yet known. Nonetheless, it was concluded from the above study that the presence of a grain boundary glassy phase may not be a prerequisite for superplastic ceramics.

Table 1 Chemical composition (at\%) at grain boundaries and in the bulk of Y-TZP using XPS

\begin{tabular}{lcccc} 
& $\mathrm{Y}$ & $\mathrm{Zr}$ & $\mathrm{C}$ & $\mathrm{O}$ \\
\hline Fractured Y-TZP & 2.0 & 18 & 28 & 52 \\
Bulk Y-TZP & 1.8 & 25.4 & 13.7 & 59.1 \\
\hline
\end{tabular}

Although the presence of a liquid phase at grain boundaries is not a necessary prerequisite for superplasticity in ceramics, its presence can definitely affect grain boundary sliding. For example, Wakai et al. have demonstrated that the temperature for superplasticity in 3Y-TZP can be reduced by doping manganese oxide $(\sim 3 \mathrm{~mol} \%)$ into the material to create a grain-boundary glassy phase [29]. Hwang and Chen [28] examined the effect of various dopants on the sintering and superplastic forming temperatures of Y-TZP and found that a minor addition $(0.3 \mathrm{~mol} \%)$ of CuO to Y-TZP could lower the sintering temperature without significantly increasing the grain size. The $\mathrm{CuO}$ doped Y-TZP can be even formed superplastically at $1150^{\circ} \mathrm{C}$. Evidently, the creation of glassy phases via oxide doping can greatly enhance the diffusion processes in, as well as the deformation rate of, superplastic ceramics. The optimum volume fraction of the liquid phase, as pointed out by Hermannsson et al., is not important, once it is beyond a critical value.[30]. Also, the volume fraction of the liquid phase is apparently not related directly to the thickness of the liquid film at grain boundaries. Further systematic studies are still needed to provide a general understanding in this area. 
Studies of superplastic $\mathrm{Al}_{2} \mathrm{O}_{3}$ were first carried out by Carry and his group [11]. As a result of this work, a fine grain size $(\sim 0.66 \mu \mathrm{m}) \mathrm{Al}_{2} \mathrm{O}_{3}$ was shown to exhibit a rupture elongation of $65 \%$ at $1450^{\circ} \mathrm{C}$ under an applied stress of $20 \mathrm{MPa}$. The flow behavior of the material was not fully characterized and, therefore, the deformation mechanisms could not be assessed. However, it was indicated that the tensile elongation, as well as the flow stresses, strongly depended on the grain size in $\mathrm{Al}_{2} \mathrm{O}_{3}$. Specifically, the tensile elongation systematically increases with a decrease in grain size. Also, the flow stress is proportional to the grain size raised to a 1.5 power, i.e., $\sigma \propto \mathrm{d}^{1.5}$ [11]. These results were proposed to be indicative of a grain boundary sliding deformation mechanism. In this fine-grained $\mathrm{Al}_{2} \mathrm{O}_{3}$, severe grain growth, and in particular dynamic grain growth, was observed within the superplastic temperature range $\left(1350-1500^{\circ} \mathrm{C}\right)[31,32]$. Grain growth was found to follow a $t^{1 / 3}$ kinetic grain growth law suggesting solute drag as the rate contolling mechanism. These results are similar to those observed in 3Y-TZP. Recently, Xue et al. [33] have shown that the addition of $\mathrm{ZrO}_{2}$ can greatly stabilize the grain structure of $\mathrm{Al}_{2} \mathrm{O}_{3}$ during superplastic deformation. A 10 vol\% $\mathrm{ZrO}_{2}-\mathrm{Al}_{2} \mathrm{O}_{3}$ (with a grain size $\sim 0.5 \mu \mathrm{m}$ ) was successfully stretched under biaxial tension at $1400^{\circ} \mathrm{C}$. Since alumina is one of the most widely used structural ceramics, future research in this material is expected to be active.

Wang and Raj [13] studied the deformation mechanisms of two fine-grained (grain sizes from 0.91 to $2 \mu \mathrm{m}$ ) lithium aluminosilicate $\beta$-spodumene glass-ceramics (containing 4 to 9 vol\% of liquid phase) and observed superplasticity in both materials. Tensile elongations of $135 \%$ and $400 \%$ were recorded from the two materials tested at a strain rate of $10^{-4} \mathrm{~s}^{-1}$ and at temperatures between 1150 and $1200^{\circ} \mathrm{C}$. It is noted that the temperature range within which superplasticity was observed is above the solidus temperatures of the test materials. The results showed that the stress exponent is 1 and $\dot{\varepsilon} \propto \mathrm{d}^{-3}$, where $\dot{\varepsilon}$ is the strain rate and $\mathrm{d}$ is the grain size; it was concluded that the deformation was limited by the diffusion of atoms through the liquid phase, a process which was modeled by Raj [34]. These experimental results illustrate that the presence of glassy phases can significantly enhance mass flow and change the plastic flow properties in a ceramic.

In the case of ceramic composites, Wakai et al. [15] first showed that some ceramic composites based on fine-grained zirconia, e.g., $20 \% \mathrm{Al}_{2} \mathrm{O}_{3} / \mathrm{Y}$-TZP, were superplastic. Nieh and Wadsworth [35] further demonstrated that a maximum elongation of $625 \%$ was obtained from the material tested at $1650^{\circ} \mathrm{C}$ and at a strain rate of $4.0 \times 10^{-4} \mathrm{~s}^{-1}$. Deformation properties, e.g., the strain rate sensitivity and activation energy, of $20 \% \mathrm{Al}_{2} \mathrm{O}_{3} / \mathrm{YTZ}$ were characterized by Wakai and Kato and Nieh and Wadsworth. The strain rate sensitivity value for the composite was determined to be about 0.5 and remained constant throughout the temperatures range from 1250 to $1650^{\circ} \mathrm{C}$. This, combined with the observation that the microstructure of superplasticaily-deformed samples remains essentially equiaxed, has led to a conclusion that the dominant deformation mechanism is grain boundary sliding. However, although a similar $\mathrm{m}$ value is measured for both Y-TZP and 
$\mathrm{Al}_{2} \mathrm{O}_{3} / \mathrm{YTZ}$ materials, the activation energy for $\mathrm{Al}_{2} \mathrm{O}_{3} / \mathrm{YTZ}$ is much less (510 [9] and $257 \mathrm{~kJ} / \mathrm{mol}$ [35] for $\mathrm{Y}$-TZP and $\mathrm{Al}_{2} \mathrm{O}_{3} / \mathrm{YTZ}$, respectively).

In terms of grain boundary sliding, three different types of grain boundary sliding can occur in $\mathrm{A}_{2} \mathrm{O}_{3} / \mathrm{YTZ}$, i.e., at $\mathrm{ZrO}_{2} / \mathrm{ZrO}_{2}, \mathrm{Al}_{2} \mathrm{O}_{3} / \mathrm{Al}_{2} \mathrm{O}_{3}$, a.d $\mathrm{Al}_{2} \mathrm{O}_{3} / \mathrm{ZrO}_{2}$ boundaries. Because of different chemical compositions and orientations, the sliding mobility for each boundary combination is expected to be different. Amongst these three boundaries, since $\mathrm{Al}_{2} \mathrm{O}_{3}$ is the minor phase, the deformation strain contribution resulting from sliding of the $\mathrm{Al}_{2} \mathrm{O}_{3} / \mathrm{Al}_{2} \mathrm{O}_{3}$ boundary is probably insignificant. The total deformation strain is then essentially an addition of the individual sliding strains from the $\mathrm{ZrO}_{2} / \mathrm{ZrO}_{2}$ and $\mathrm{Al}_{2} \mathrm{O}_{3} / \mathrm{ZrO}_{2}$ interfaces.

To evaluate the relative sliding mobilities of the $\mathrm{ZrO}_{2} / \mathrm{ZrO}_{2}$ and $\mathrm{Al}_{2} \mathrm{O}_{3} / \mathrm{ZrO}_{2}$ interfaces, flow stress as a function of strain rate for both superplastic $\mathrm{Y}-\mathrm{TZP}$ and $\mathrm{Al}_{2} \mathrm{O}_{3} / \mathrm{YTZ}$ at $1550^{\circ} \mathrm{C}$ is given in Fig. 10. It is noted in the figure that, except in the high strain rate region, the mechanical strength of the $\mathrm{Al}_{2} \mathrm{O}_{3} / \mathrm{YTZ}$ composite is lower than that of Y-TZP. In addition, the larger grain size $(\sim 0.5 \mu \mathrm{m})$ in the composite, as compared to that $(\sim 0.3 \mu \mathrm{m})$ in the $\mathrm{Y}-\mathrm{TZP}$, is expected to give rise to a strengthening effect $\left(\sigma \propto \mathrm{d}^{3 / 4}\right.$ for $\mathrm{Al}_{2} \mathrm{O}_{3} / \mathrm{YTZ}$ [35]) in the composite. However, an almost inverse trend is displayed in Fig. 10. This suggests that the sliding mobility of the $\mathrm{Al}_{2} \mathrm{O}_{3} / \mathrm{ZrO}_{2}$ interface is probably higher than that of the $\mathrm{ZrO}_{2} / \mathrm{ZrO}_{2}$ interface. Such a conclusion is consistent with the fact that the activation energy for superplasticity of $\mathrm{Al}_{2} \mathrm{O}_{3} / \mathrm{YTZ}$ is much lower than the activation energy for superplasticity of monolithic Y-TZP.

In fine-grained superplastic materials, the deformation processes involve not only grain boundary sliding but also grain rotation, in order to accomodate the large plastic strains. Different sliding mobilities between $\mathrm{Al}_{2} \mathrm{O}_{3} / \mathrm{ZrO}_{2}$ and $\mathrm{ZrO}_{2} / \mathrm{ZrO}_{2}$ interfaces are expected to result in strain incompatibilities at triple junctions, and thus cavitation. Therefore, $\mathrm{Al}_{2} \mathrm{O}_{3} / \mathrm{YTZ}$ is expected to be more susceptible to cavitation and less ductile than monolithic Y-TZP; this is shown to be the case in Fig. 11 in which cavitation is plotted as a function of true local strain [36].

In another recent study by Wakai et al. [37], a fine-grained silicon carbide/silicon nitride composite has been shown to exhibit superplastic behavior. An elongation-to-failure (150\%) and a stress exponent of 2 was measured in this $\mathrm{SiC}_{S} \mathrm{Si}_{3} \mathrm{~N}_{4}$ composite. This composite was prepared initially from an amorphous $\mathrm{Si}-\mathrm{C}-\mathrm{N}$ powder produced by vapor phase reaction of $\left[\mathrm{Si}\left(\mathrm{CH}_{3}\right)_{3}\right]_{2} \mathrm{NH} / \mathrm{NH}_{3} / \mathrm{N}_{2}$ at $1000^{\circ} \mathrm{C}$. Bulk samples were prepared by mixing the amorphous powder with $6 \mathrm{wt} \% \mathrm{Y}_{2} \mathrm{O}_{3}$ and $2 \mathrm{wt} \% \mathrm{Al}_{2} \mathrm{O}_{3}$ as sintering aids, and further hot pressing at $1650^{\circ} \mathrm{C}$ and ${ }^{\star} 34 \mathrm{MPa}$ in $\mathrm{N}_{2}$. The above processes resulted in a composite with approximately $20 \mathrm{wt} \% \mathrm{SiC}$. It is particularly pointed out that a substantial amount of intergranular liquid phase was present in the case of this composite. The deformation mechanisms are yet to be fully specified. The microstructure of the composite is noted to consist of both spherical grains $(<0.2 \mu \mathrm{m})$ and elongated grains $(<0.5 \mu \mathrm{m})$. The presence of elongated grains were found to be detrimental to the 
superplastic properties. A similar effect was also reported for an $\mathrm{Al}_{2} \mathrm{O}_{3} /$ mullite composite by Yoon and Chen [38].

To further understand the effects of the shape of reinforcements in a composite, Dougherty et a1. [39] recently conducted a study on the niigh-temperature deformation behavior of a SiC whiskerreinforced, yttria-stabilized, tetragonal zirconia polycrystalline composite containing 20 vol.\% SiC whiskers $\left(\mathrm{SiC}_{\mathrm{W}} / \mathrm{Y}-\mathrm{TZP}\right)$. The results indicate that the addition of $\mathrm{SiC}$ whiskers to fine-grained $\mathrm{Y}-\mathrm{TZP}$ can result in a significant strengthening effect. As a result of the strengthening, the ductility of the composite is also reduced considerably. The strengthening does not result from the fact that $\mathrm{SiC}$ has a greater strength per se, but rather from the reduction in grain boundary sliding caused by the presence of $\mathrm{SiC}$ whiskers. The morphology of the reinforcements clearly plays an important role in determining the strength of a composite. For example, at $1550^{\circ} \mathrm{C}$ and a strain rate of $10^{-3} \mathrm{~s}^{-1}$, the strengths of $\mathrm{Y}$-TZP and $20 \mathrm{wt} \%$ (28 vol\%) $\mathrm{Al}_{2} \mathrm{O}_{3}$ particle-reinforced $\mathrm{Y}$-TZP are both less than $30 \mathrm{MPa}$, whereas the strength of $20 \mathrm{vol} \% \mathrm{SiC}$ whisker-reinforced Y-TZP is almost $200 \mathrm{MPa}$; this is shown in Fig. 12. Interestingly, these three materials all have a fine-grained matrix $(\sim 0.5 \mu \mathrm{m})$. It is particularly noted that although the presence of $\mathrm{SiC}$ whiskers causes a dramatic: strengthening effect, the stress exponent in the $\mathrm{SiC}_{\mathrm{W}} / \mathrm{Y}$-TZP composite is similar to that in the monolithic Y-TZP, implying that both materials deform by grain boundary sliding at elevated temperatures.

\section{High Strain Rate Superplasticity (HSRS)}

The rate of conventional superplastic forming $\left(\sim 10^{-4} \mathrm{~s}^{-1}\right)$ is relatively slow compared to many manufacturing processes $\left(10^{0}-10^{2} \mathrm{~s}^{-1}\right)$ and from a commercial viewpoint the development of materials that exhibit superplasticity at fast rates is desirable. The generation of a new set of microstructural conditions to make grain-boundary sliding more facile, and to inhibit the intervention of power-law slip creep processes, can increase the maximum strain rate for superplastic flow. The most straightforward structural feature that can be modified to achieve such an enhancement in superplasticity is to decrease the grain size. When the grain size is reduced, the superplastic flow rate (by grain boundary sliding) is increased, and the normal flow rate (by slip) is reduced. Significant breakthroughs have been made in this area of High Strain Rate Superplasticity (HSRS) and high elongations have been recorded under high strain rate conditions [40-44].

HSRS was first discovered in $\mathrm{SiC}$ whisker reinforced $\mathrm{Al}$ alloys [40] and subsequently in mechanically alloyed $\mathrm{Al}$ alloys [45-49]. In the former case, a composite of $\mathrm{Al} 2124$ containing $20 \mathrm{vol} . \% \mathrm{SiC}$ whiskers was found to behave in a superplastic-like manner (up to $300 \%$ elongation) at $525^{\circ} \mathrm{C}$ and at a high strain rate of $3 \times 10^{-1} \mathrm{~s}^{-1}$. The elongations-to-failure in both the longitudinal and transverse directions as a function of strain rate for this composite at $525^{\circ} \mathrm{C}$ are given in Fig. 13. The elongation is noted to increase with increasing strain rate and a maximum value of about $300 \%$ is found at a high strain rate of $0.33 \mathrm{~s}^{-1}$. The maximum in elongation corresponds to a region showing a strain rate sensitivity, $\mathrm{m}$, of about 0.33 [40]. Rather low strain rate sensitivities $(\mathrm{m} \sim 0.1)$, 
and therefore reduced elongations to failure $(<100 \%)$, were generally observed at low strain rate regions.

In addition to $\mathrm{SiC} / \mathrm{Al}$ composites, several $\mathrm{Si}_{3} \mathrm{~N}_{4(\mathrm{w})}$ reinforced $\mathrm{Al}$ composites, prepared by powder metallurgy techniques, were subsequently demonstrated to be superplastic [42-44]. Comparative data from the $\mathrm{Si}_{3} \mathrm{~N}_{4}(w)$-reinforced composites that exhibit the HSRS phenonmenon are given in Table 2. It is evident in Table 2 that the strain rates at which superplasticity takes place $\left(\sim 0.1 \mathrm{~s}^{-1}\right)$ are similar for all the composites.

Table 2 HSRS Test Results and Conditions for Various Alloys and Composites*

Material/Reference $\quad$ Test Temp., Solidus, Strain Rate, Stress, Elong., \%

\begin{tabular}{|c|c|c|c|c|c|}
\hline & ${ }^{\circ} \mathrm{C}$ & ${ }^{\circ} \mathrm{C}$ & $\left(s^{-1}\right)$ & $(\mathrm{MPa})$ & \\
\hline$\beta \mathrm{SiC}_{\mathrm{W}} / 2124 \mathrm{Al}[40]$ & 525 & 502 & 0.3 & $\sim 10$ & $\sim 300$ \\
\hline$\beta \mathrm{Si}_{3} \mathrm{~N}_{4(w)} / 2124 \mathrm{Al}$ [42] & 525 & 502 & 0.2 & $\sim 10$ & $\sim 250$ \\
\hline$\alpha \mathrm{Si}_{3} \mathrm{~N}_{4(\mathrm{w})} / 7064 \mathrm{Al}$ & 525 & $\sim 525$ & 0.2 & $\sim 15$ & $\sim 250$ \\
\hline$\beta \mathrm{Si}_{3} \mathrm{~N}_{4(w)} / 6061 \mathrm{Al}[43]$ & 545 & 582 & 0.5 & $\sim 20$ & $\sim 450$ \\
\hline IN $9021[46]$ & 475 & 495 & 1 & & $\sim 300$ \\
\hline IN $9021[50]$ & 550 & 495 & 50 & & $\sim 1250$ \\
\hline IN $90211[47]$ & 475 & 495 & 2 & & -500 \\
\hline $\mathrm{MA} \mathrm{SiC}_{(\mathrm{p})} / \mathrm{IN} 9021$ [45] & 550 & 495 & 10 & $\sim 7$ & $\sim 500$ \\
\hline $7475 \mathrm{Al}-0.7 \mathrm{wt} \% \mathrm{Zr}[50]$ & 520 & $<538$ & 0.3 & & $\sim 900$ \\
\hline
\end{tabular}

* Subscripts $(w)$ and $(p)$ denote whisker and particulate reinforcement, respectively.

It should be pointed out that not all $\mathrm{Si}_{3} \mathrm{~N}_{4(w)} / \mathrm{Al}$ composites exhibit the HSRS phenomenon. Table 3 lists the $\mathrm{SiC}$ or $\mathrm{Si}_{3} \mathrm{~N}_{4}(w)$-reinforced composite combinations that are superplastic and nonsuperplastic. As shown in Table 3, specific combinations of tatrix and whiskers in a MMC are critical to the development of HSRS. A simple criterion for superplasticity based on the individual types of whisker or alloy matrix appears to be impossible. This viewpoint is supported by the observation that $\beta \mathrm{Si}_{3} \mathrm{~N}_{4(w)} / 2124$ and $\beta \mathrm{Si}_{3} \mathrm{~N}_{4} / 6061$ are superplastic, but $\alpha \mathrm{Si}_{3} \mathrm{~N}_{4}\left(w_{1}\right) / 2124$ and $\beta$ SiC/6061 are not. It is of particular importance to point out the fact that none of the unreinforced $2124 \mathrm{Al}, 7064 \mathrm{Al}$, and $6061 \mathrm{Al}$ matrix alloys was superplastic at high strain rates. 
Table 3 List of Superplastic and Non-Superplastic Matrix/Whisker Composite Combinations

\begin{tabular}{|c|c|c|}
\hline Matrix & Whisker & Superplastic? \\
\hline $2124 \mathrm{Al}$ & $\beta \mathrm{Si}_{3} \mathrm{~N}_{4}$ & yes \\
$6061 \mathrm{Al}$ & $\beta \mathrm{Si}_{3} \mathrm{~N}_{4}$ & yes \\
$7064 \mathrm{Al}$ & $\alpha \mathrm{Si}_{3} \mathrm{~N}_{4}$ & yes \\
$2124 \mathrm{Al}$ & $\alpha \mathrm{Si}_{3} \mathrm{~N}_{4}$ & no \\
$2124 \mathrm{Al}$ & $\beta \mathrm{SiC}$ & yes \\
$6061 \mathrm{Al}$ & $\beta \mathrm{SiC}$ & no \\
\hline
\end{tabular}

\section{Origin of HSRS}

The fact that HSRS was observed in both $\beta \mathrm{SiC} / 2124$ and $\beta \mathrm{Si}_{3} \mathrm{~N}_{4} / 2124$, but not in unreinforced $2124 \mathrm{Al}$, demonstrates the importance of the presence of whiskers. In principle, the presence of whiskers in an alloy can produce at least two microstructural effects. First, their presence can produce and maintain a stable, fine matrix grain size. Second, a large number of whisker-matrix interfaces are created.

\section{Grain Size}

The constitutive or phenomenological equations for superplastic flow and slip creep are generally expressed as [51],

$$
\dot{\varepsilon}=\mathrm{A} \cdot \mathrm{d}^{-\mathrm{p}} \cdot \mathrm{D} \cdot\left(\frac{\sigma}{\mathrm{E}}\right)^{\mathrm{n}}
$$

where $\dot{\varepsilon}$ is the strain rate, $D$ is the diffusivity, $d$ is the grain size, $\sigma$ is the stress, $E$ is the modulus, $n$ is the stress exponent, $\mathrm{p}$ is the grain size dependence, which is typically $2-3$, and $\mathrm{A}$ is a material constant. According to Eq. (1), refinement of the grain size by a factor of 2 would be expected to increase the optimum strain rate for superplastic flow by a factor of from 4 to 8 depending upon the precise grain size relationship as described above. The grain size effect was illustrated in Fig. 2.

\section{Interfaces}

The fracture surfaces of HSRS specimens usually exhibit extensive fiber pull out, indicating that extensive interfacial sliding has taken place during superplastic deformatıon. This observation suggests that microstrucxural characteristics at interfaces between the matrix and the fibers are equally as important as grain boundaries in superplastic deformation. In both $\mathrm{SiC} / \mathrm{Al}$ and $\mathrm{Si}_{3} \mathrm{~N}_{4} / \mathrm{Al}$, the diameters $(\sim 1 \mu \mathrm{m})$ of $\mathrm{SiC}$ and $\mathrm{Si}_{3} \mathrm{~N}_{4}$ whiskers (or particulates) are both similar to the grain size of the matrix alloys. To a first order of approximation, and from an interface sliding point of view, 
one could to some extent perhaps treat the whiskers as individual grains. If this was the case, then the grain size effect applied to alloys would be expected to be mechanistically also applicable to composites.

It is pointed out in Table 1 and Fig. 13 that the data for $\beta \mathrm{SiC}_{\mathrm{w}} / 21.24 \mathrm{Al}$ were measured at a temperature of $525^{\circ} \mathrm{C}$ which is above the solidus temperature of the $2124 \mathrm{Al}$ matrix. (The solidus temperature for the $2124 \mathrm{Al}$ is $50,2^{\circ} \mathrm{C}$.) In fact, it is especially noted in Table 1 that, despite some subtle differences in the experimental procedures and results, the tests were performed at temperatures near to or above the matrix solidus temperatures of the materials. In other words, materials were usually tested in a semi-solid state. (Some materials may have been tested at a nominal temperature which is slightly lower than the solidus. Because of the extremely fast strain rates, however, the effective temperature is expected to be significantly higher than the nominal test temperature, as a result of adiabatic heating.)

Mechanistically, the deformation properties (or viscous properties) of a material can be altered dramatically, with the pre. ince of even a small amount of liquid phase. For example, Pharr \& Ashby [52] have demonstrated that the deformation characteristics of a crystalline solid containing liquid phases, in which the liquid phases act as lubricants to ir mote grain and particle sliding, can be drastically changed. Such a result is expected to prevail, particularly in fine-grained materials, since grain rearrangement, which involves sliding and rotation is easior between fine grains as compared to coarse grains. The situation is similar to that occurring during the rheocasting (or semi-solid metal forming) of a metal [53]. Both cases can be described in rheological terms. From a rheological viewpoint then, the shear viscosity $\eta$, of a semi-solid is defined by

$$
\eta=\tau / \dot{\gamma}
$$

where $\tau$ is the shear stress, and $\dot{\gamma}$ is the shear strain rate.

A fluid containing a suspension of particles normally behaves like a non-Newtonian fluid. For a non-Newtonian fluid, $\eta$ is not a constant, but instead is itself a function of shear rate (or stress), i.e.

$$
\eta=\mathrm{fn}(\dot{\gamma})
$$

(Strictly speaking, the rheological behavior of a non-Newtonian fluid is also dependent upon "structural parameters", e.g., the volume fraction, shapes, size distribution, and, sometimes, charges on the particles. For a brief review on this subject, see Ref.54.) Eqn.(3) can usual!y be expressed by a power law

$$
\eta=K \cdot \dot{\gamma}^{-p}
$$


where $\mathrm{K}$ and $\mathrm{p}$ (the power law index) are both material constants. A fluid is classified as shear thinning (pseudoplastic) when $\mathrm{p}>0$, and as shear thickening when $\mathrm{p}<0$. (For a Newtonian fluid, $\mathrm{p}=0$.) Comivining Eqns. (2) and (4) yields

$$
\tau=\mathrm{K} \cdot \dot{\gamma}^{\mathrm{m}}
$$

where $m=1-p$ is the strain rate sensitivity of a material. This type of equation is often used to describe the high-temperature deformation of structural materials.

Experimentally, Moon [55] has measured the steady-state viscosity of a Al-6.5 wt\%Si alloy at a temperature when the solid volume fraction was 0.4. In addition, Moon measured the viscosities of several SiC particulate-reinforced Al-6.5 wt\%Si metal-matrix composites (with 10, 20, and 30 vol\% $\mathrm{SiC}$ ) as a function of shear rate at $700^{\circ} \mathrm{C}$. The results obtained from these composites are represented in Fig. 14. A shear thinning effect was observed in both the alloy and the composites. Also, despite a slight difference in their apparent viscosity values, the $\mathrm{p}$ values for the alloy and the 30 vol\% SiC-containing composite were calculated to be 0.88 and 0.61 , respectively. (The p values for the 10 vol\% and 20 vol\% SiC-containing composites are 0.40 and 0.58 , respectively.) These $\mathrm{p}$ values, in turn, give rise to $\mathrm{m}$ values of $0.6,0.42$, and 0.39 for the $10 \mathrm{vol} \%, 20 \mathrm{vol} \%$, and 30 vol\% SiC-containing composites, respectively, whereas the $\mathrm{m}$ value for the alloy itself is only 0.12 . It is especially noted that the above results were all obtained at very high shear strain rates ( $\dot{\gamma} \sim 200$ $1000 \mathrm{~s}^{-1}$ ). These shear strain rates are similar to those at which HSRS has been observed as tabulated previously. It is also important to note that the above $\mathrm{m}$ values for the composites are very close to those $(\sim 0.3$ to 0.5$)$ obtained from HSRS studies.

Large tensile elongations are recorded in metals exhibiting high strain rate sensitivity values (typically > 0.3); the high elongations are attributed to the material's resistance to local necking upon deformation because of the high strain rate sensitivity [56]. Assuming such a criterion also holds in the semi-solid state, then a composite in such a state would be expected to show large elongations under appropriate test conditions. Furthermore, in terms of rheological flow, the exact forms of the solid phase in the solid-liquid mixture are not of primary importance. If the presence and distribution of the solid phase yields an appropriate fluidity (or viscosity) in a solid-liquid mixture, i.e., it shows a $\mathrm{p}$ value that is approximately iess than 0.7 , then such a mixture would also be expected to exhibit a large elongation, provided a fracture mechanism such as gross decohesion does not intervene. This may be the reason that a very fine grain size is required for HSRS. For a given volume fraction of liquid phase, and for the case where this volume fraction is small, a fine grain size can produce a higher capillarity force between crystalline grains, as the result of a reduced amount of liquid per grain boundary area. This offers an possible explanation for the observations of HSRS in the MMCs listed in Table 2. It is also worth noting in Table 2 that HSRS 
takes place in both whisker- and particulate-reinforced composites, and in both the transverse and longitudinal directions of the whisker reinforced composites. This result inuicates that, despite the highly anisotropic nature of whiskers, compared with even irregular particulates, the rheological flow properties of these two types of materials are not much different.

A question arises regarding some of the data in Table 2, and especially those that have test temperatures that appear to be below the solidus of the alloy matrix. Nieh and Wadsworth [40] have demonstrated that the plastic flow characteristics, in particular, the strain rate sensitivity value, of $20 \mathrm{vol} \% \mathrm{SiC} / 2124 \mathrm{Al}$ (solidus $=505^{\circ} \mathrm{C}$ ) remain virtually ur.changed from 475 to $550^{\circ} \mathrm{C}$; this is shown in Fig. 15. In other words; the plastic flow characteristics do not exhibit a discontinuity across the solidus temperature. This result seems initially to contradict the suggestion that the presence of partial liquid phase may be a unique contributing factor to the observed superplasticity.

To resolve this issue, there are two factors - adiabatic heating during high rate deformation, and solute redistribution, that must be considered. The temperature rise during the high strain rate testing of $\mathrm{SiC} / 2124$ is estimated to be at least $15^{\circ} \mathrm{C}$ (this assumes that no localized heating takes place). Therefore, although the apparent test temperature is $475^{\circ} \mathrm{C}$, the actual temperature is certainly higher. The other factor, which can also contribute to the presence of a liquid phase, is related to solute segregation at a reinforcement-matrix interface. Numerous reports have shown that the presence of ceramic reinforcements can influence solute distributions in an Al alloy. For example, Nutt and Carpenter [57], in their study of a $15 \mathrm{vol} \% \mathrm{SiC}_{\mathrm{w}} / 2124$ composite, first pointed out that the chemical composition at the SiC/Al interface was substantially different from that in the bulk matrix. Specifically, the SiC/Al alloy inierface was enriched in $\mathrm{Mg}$ and $\mathrm{Cu}$. Most recently, Strangwood et al. [58] have used a special FEM/STEM technique to study solute segregation to $\mathrm{SiC} / \mathrm{Al}$ alloys interfaces and showed that the $\mathrm{Mg}$ and $\mathrm{Cu}$ concentrations at the $\mathrm{SiC} /$ matrix interfaces in an underaged $15 \mathrm{vol} \% \mathrm{SiC}_{\mathrm{p}}-2 \times x \times \mathrm{Al}(1.45$ at $\% \mathrm{Cu}, 1.67$ at $\% \mathrm{Mg}, 0.12$ at $\% \mathrm{Zr}, 0.1$ at $\% \mathrm{Mn})$ could reach approximately 4.5 and 9 at\%, respectively; this is shown in Fig. 16. Both the $\mathrm{Mg}$ and $\mathrm{Cu}$ segregation are expected to reduce the local melting point of the $\mathrm{Al}$ matrix near the interface region.

Therefore, although the test temperature of $475^{\circ} \mathrm{C}$ in Fig. 15 (for $\mathrm{SiC} / 2124 \mathrm{Al}$ ) appears to be within the solid range of $2124 \mathrm{Al}$, the $\mathrm{Mg}$ segregation may be sufficiently high to result in local melting at the $\mathrm{SiC} / \mathrm{Al}$ interface. For example, a $\mathrm{Mg}$ concentration of over 6.5 at\% at the interface can by itself result in localized melting at $475^{\circ} \mathrm{C}$, even in the absence of adiabatic heating from high strain rate deformation. (The effects of $\mathrm{Mg}$ and $\mathrm{Cu}$ on the melting point of $\mathrm{Al}$ are estimated to be approximately $-6^{\circ} \mathrm{C} / \mathrm{at} \% \mathrm{Mg}$ and $-6.5^{\circ} \mathrm{C} / \mathrm{at} \% \mathrm{Cu}$ [59]). Therefore, the HSRS phenomenon may occur in the presence of some liquid, even though the temperature appears to be below the solidus in a particular $\mathrm{SiC} / \mathrm{Al}$ or $\mathrm{Si}_{3} \mathrm{~N}_{4} / \mathrm{Al}$ composite. 
As mentioned previously, an ultrafine-gra ${ }^{\circ}$ ed $(\sim 0.5 \mu \mathrm{m})$, mechanivally alloyed $\mathrm{Al} 9021$ was first observed to exhibit superplastic elongations ai strain rates as high as $2 \mathrm{~s}^{-1}$ by Nich, Gilman, and Wadsworth [45]. In subsequent detailed studies by Bieler, Nieh, Wadsworth, and Mukherjee [46], on a similar material, an optimum elongation of $500 \%$ was found at a strain rate of $2.5 \mathrm{~s}^{-1}$. Most recently, Higashi [49] has independently measured an elongation of $1000 \%$ at $50 \mathrm{~s}^{-1}$ and $700 \%$ at $10^{2} \mathrm{~s}^{-1}$ in $\mathrm{Al} 9021$. In addition to Al 9021, mechanically alloyed Ni-base alloys (MA 754 and IN 6000 ) have also been noted to exhibit high ductility at high strain rates by Gregory, Gibeling, and Nix [60]. The precise, operative, deformation mechanisms in these materials are under investigation. Nonetheless, the overwhelming effects of grain size on the optimum strain rate are clearly demonstrated in Fig. 2.

\section{Fracture Behavior in Ceramics Versus Metals}

It was recently pointed out by Kim et al. [61] and Chen and Xue [2] that the maximum tensile elongation of a superplastic ceramic is directly related to the flow stress, rather than to the strain rate sensitivity value. This is because polycrystalline ceramics are susceptible to grain boundary separation. Therefore, it is possible that in historical studies of ceramic oxides, in which superplastic characteristics were determined in compression that negligible ductility in tension may occur. Clearly this uncertainty should be clarified with appropriate additional experimental studies.

In an attempt to understand the parameters controlling the optimum superplastic strain, in an $\mathrm{Fe} / \mathrm{FeC}_{3}$ composite as well as $3 \mathrm{Y}-\mathrm{TZP}, \mathrm{Al}_{2} \mathrm{O}_{3} / \mathrm{YTZ}$, and $\mathrm{Al}_{2} \mathrm{O}_{3}$, Kim et al. [61] have correlated the maximum tensile elongation as a function of temperature-compensated strain rate, i.e. $\dot{\varepsilon} \exp (\mathrm{Q} / \mathrm{RT})$, for a number of superplastic ceramics; this result is shown in Fig. 17. Assuming that the plastic flow of superplastic ceramics can be described by the Dorn equation, Fig. 17 essentially indicates that tensile elongation is determined by flow stress. When the flow stress is lower than the grain boundary strength of a material, intergranular failures do not occur and the material deforms plastically. As the flow stress is increased, so is the likelihood that the cohesive strength of grain boundaries will be reached. Once this level of stress is attained, intergranular cavitation and cracking occur, and the elongation to failure is decreased.

\section{SUMMARY}

Superplasticity is a flourishing field of study that is very broad in the range of materials it covers, and the span of interest extends from basic research to engineering applications. The immediate future for the field is very exciting, in part because of the discovery of superplasticity in ceramic based materials and the discovery of high strain rate superplasticity in metallic based materials. 


\section{ACKNOWLEDGMENT}

The authors would like to acknowledge financial support from the Army Research Office under Contract No. DAAL03-89-C-0028, and the U.S. Department of Energy contract No. W-7405-Eng48, at Lawrence Livermore National Laboratory.

\section{REFERENCES}

1. T.G. Langdon and J. Wadsworth, in S. Hori, M. Tokizane, and N. Furushiro (eds.), Superplasticity in Advanced Materials, , The Japan Society for Research on Superplasticity, Osaka, Japar, 1991, p. 847.

2. I.-W. Chen and L.A. Xue: J. Am. Ceram. Soc., 73 (1990) 2585.

3. F. Wakai, Y. Kodama, and T. Nagano: Japan J. Appl. Phy., Series 2, Lattice Defects in Ceramics, (1989) 57.

4. F. Wakai: Brit. Ceram. Trans. J., 88 (1989) 205.

5. Y. Maehara and T.G. Langdon: J. Mater. Sci., 25 (1990) 2275.

6. T.G. Nieh, J. Wadsworth, and F. Wakai, Inter. Mater. Rev., 36(4) (1991) 146.

7. F. Wakai, S. Sakaguchi, and Y. Matsuno: Adv. Ceram. Mater., 1 (1986) 259.

8. T. Hermansson, K.P.D. Lagerlof, and G.L. Dunlop: in C.H. Hamilton and N.E. Paton (eds.), Superplasticity and Superplastic Forming, TMS, Warrendale, Pennsylvania, 1988, p. 631.

9. T.G. Nieh and J. Wadsworth: Acta Metall. Mater., 38 (1990) 1121.

10. P. Gruffel, P. Carry, and A. Mocellin: in D. Taylor (ed.), Science of Ceramics - Vol. 14, The Institute of Ceramics, Shelton, UK, 1988, p. 587.

11. F. Wakai, Y. Kodama, S. Sakaguchi, and T. Nonami: J. Amer. Ceram. Soc., 73 (1990) 257.

12. J.-G. Wang and R. Raj: J. Amer. Ceram. Soc., 67 (1984) 399.

13. J.-G. Wang and R. Raj: J. Amer. Ceram. Soc., 67 (1984) 385.

14. F. Wakai and H. Kato: Adv. Ceram. Mater., 3 (1988) 71. 
15. T.G. Nieh, C.M. McNally, and J. Wadsworth: Scripta Metall., 23 (1989) 457.

16. F. Wakai: in M. Kabayashi and F. Wakai (eds.), MRS Intl. Meeting on Advanced Materials Vol 7 (IMAM-7, Superplasticity), Materials Research Society, Pittsburgh, Pennsylvania. 1989, p. 225.

17. F. Wakai, Y. Kodama, S. Sakaguchi, N. Murayama, H. Kato, and T. Nagano: in M. Kabayashi and F. Wakai (eds.), MRS Intl. Meeting on Advanced Materials Vol 7 (IMAM-7, Superplasticity), Materials Research Society, Pittsburgh, Pennsylvania, 1989, p. 259.

18. F. Wakai: in C.H. Hamilton and N.E. Paton (eds.), Superplasticity and Superplastic Forming , TMS, Warrendale, Pennsylvania, 1988, p. 619.

19 T. Kuroishi, K. Uno, and F. Wakai: in M. Kabayashi and F. Wakai (eds.), MRS Intl. Meeting on Advanced Materials Vol 7 (IMAM-7, Superplasticity), Materials Research Society, Pittsburgh, Pennsylvania, 1988, p. 267.

20. F. Wakai, Y. Kodama, S. Sakaguchi, N. Murayama, K. Izaki, and K. Niihara: Nature, 344 (1990) 421.

21. F. Wakai, Y. Kodama, S. Sakaguchi, N. Murayama, K. Izaki, and K. Niihara: in M.J. Mayo, M. Kobayashi, and J. Wadsworth (eds.), Superplasticity in Metals, Ceramics, and Intermetallics , (MRS \#. 196R), Materials Research Society, Pittsburgh, Pennsylvania, 1990, p. 349.

22. W.J. Kim, J. Wolfenstine, G. Frommeyer, and O.D. Sherby: Scripta Metall., 23 (1989) 1515

23. J.P. Wittenauer, T.G. Nieh, and J. Wadsworth, Scripta Metall. Mater., 26(4) (1992) 551.

24. T.G. Nieh and J. Wadsworth, J. Amer. Ceram. Soc., 72[8] (1989) 1469.

25. J.W. Cahn, Acta Metall., 10 (1962) 789.

26. R.J. Brook, Scripta Metall., 2 (1968) 375.

27. T.G. Nich, D.L. Yaney, and J. Wadsworth, Scripta Metall., 23 (1989) 2007.

28. C-M.J. Hwang and I.W. Chen: J. Amer. Ceram. Soc., 73 (1990) 1623.

29. F. Wakai, H. Okamura, N. Kimura, and P.G.E. Descamps: in N. Igata et al. (eds.), Proc. 'Ist Japan International SAMPE Symp., SAMPE, Covina, California, 1989, p. 267. 
30. T. Hermansson, H. Swan, and G. Dunlop: in G. de With, R.A. Terstra, and R. Metselaar, (eds.), Euro-Ceramics Vol. 3', Elsevier Applied Science, London-New York, 1989, p. 3.323.

31. J.D. Fridez, C. Carry, and A. Mocellin: in W.D. Kingery (ed.), Advances in Ceramics Vol. 10 - Structure and Properties of $\mathrm{MgO}$ and $\mathrm{Al}_{2} \mathrm{O}_{3}$ Ceramics, American Ceramic Society, Columbus, Ohio, 1984, p.720.

32. C. Carry and A. Mocellin: in P. Vincenzini (ed.), High Tech Ceramics, Elsevier Science Publishers B.V., Amsterdam, 1987, p.1043.

33. L.A. Xue, X. Wu, and I.W. Chen: J. Amer. Ceram. Soc., 74 (1991) 842.

34. R. Raj: J. Geophys. Res., 87 [B6] (1982) 4731.

35. T.G. Nieh and J. Wadsworth, Acta Metall. Mater., 39(12) (1991) 3037.

36. D.J. Schissler, A.H. Chokshi, T.G. Nieh, and J. Wadsworth, Acta Metall. Mater., 32(12) (1991) 3227.

37. F. Wakai, Y. Kodama, S. Sakaguchi, N. Murayama, K. Izaki, and K. Niihara: Nature, 344 (1990) 421.

38. C.K. Yoon and I.W. Chen, J. Am. Ceram. Soc., 73[6] (1990) 1555.

39. Sara E. Dougherty, Tai-Gang Nieh, Jeffrey Wadsworth, and Yoshio Akimune, J. Amer. Ceram. Soc. (1992). in press.

40. T.G. Nieh, C.A. Henshall, and J. Wadsworth, Scripta Metall., 18 (1984) 1405 .

41. J. Wadsworth, T.G. Nieh, C.A. Henshall, A.R. Pelton, and P.S. Gilman, in G.J. Hildeman and M.J. Koczak (eds.), High Strength Powder Metallurgy Aluminum Alloys II, TMS-AIME, Warrendale, Pennsylvania, (1986), p.137.

42. T. Imai, M. Mabuchi, Y. Tozawa, and M. Yamada, J. Mater. Sci. Lett., 9 (1990) 255.

43. M. Mabuchi and T. Imai, J. Mater. Sci. Lett., 9 (1990) 763.

44. M. Mabuchi, T. Imai, K. Kubo, K. Higashi, Y. Okada, and S. Tanimura, Mater. Lett., 10 (1991) 339.

45. K. Higashi, T. Okada, T. Mukai, S. Tanimura, T.G. Nieh, and J. Wadsworth, Scripta Metall. Maters., 26 (1992) 185. 
46. T.G. Nieh, P.S. Gilman, and J. Wadsworth, Scripta Metall., 19 (1985) 1375.

47. T.R. Bieler, T.G. Nieh, J. Wadsworth, and A.K. Mukherjee, Scripta Metall., 22 (1988) 81.

48. K. Higashi, T. Okada, 'T. Mukai, and S. Tanimura, Scripta Metall. Mater. 26 (1992) 761.

49. K. Higashi, T. Okada, T. Mukai, and S. Tanimura, Scripta Metall. Mater., 25 (1991) 2053.

50. N. Furushiro and S. Hori, in M.J. Mayo, M. Kobayashi, and J. Wadsworth (eds.), Superplasticity in Metals, Ceramics, and Intermetallics, (MRS \#. 196R), Materials Research Society, Pittsburgh, Pennsylvania, 1990, p. 249.

51. O.D. Sherby and J. Wadsworth, Prog. Mater. Sci., 33 (1990) 169.

52. G.M. Pharr and M.F. Ashby, Acta Metall., 31 (1983) 129.

53. M.C. Flemings, Metall. Traris., 22A (1991) 957.

54. D.J. Jeffrey and A. Acrivos, J. Am. Inst. Chem. Engr., 22(3) (1974) 417.

55. H.-K. Moon, Ph.D. dissertation, Massachusetts Institute of Technology, 1990.

56. D. A. Woodford, Trans. ASM Quarterly, 62 (1969) 291.

57. S.R. Nutt and R.W. Carpenter, Mater. Sci. Eng., 75 (1985) 169.

58. M. Strangwood, C.A. Hippsley, and J.J. Lewandowski, Scripta Metall. Mater., 24 (1990) 1483.

59. Binary Alloy Phase Diagrams, Vol. 1, edited by T. Massalski, J.L. Murray, L.H. Bennett, and H. Baker, ASM, Metals Park, Ohio, (1986).

60. J.K. Gregory, J.C. Gibeling, and W.D. Nix, Metall. Trans., 16A, (1985) 777.

61. W.J. Kim, J. Wolfenstine and O.D. Sherby: Acta Metall. Mater., 39 (1991) 199. 


\section{Figure Captions}

Fig. 1 Modulus-compensated, plastic flow stress as a function of diffusion-compensated, strain rate for tetragonal zirconia. It is evident that flow stress decreases as grain size decreases.

Fig. 2 An overview of the superplastic behavior of metal alloys to demonstrate the grain size effect.

Fig. 3 Examples of superplastically-formed ceramic (Y-TZP) articles including a cone-oncylinder geometry, a hat section, and a hemisphere.

Fig. 4 Transmission electron micrograph of $3 \mathrm{Y}-\mathrm{YTZ}$ ceramic showing the extremely fine grain size of about $0.2-0.3 \mu \mathrm{m}$. The microstructure consists of equilibrated, hexagonal-shaped grains with sharp apexes.

Fig. 5 Comparison of a superplastically deformed Y-TZP sample (800\%) and a superplastically deformed $\mathrm{Al}_{2} \mathrm{O}_{3} / \mathrm{YTZ}(625 \%)$ with an undeformed sample.

Fig. 6 Stress as a function of strain rate for $\mathrm{Al}_{2} \mathrm{O}_{3} / \mathrm{YTZ}$. The strain rate sensitivity exponent is approximately 0.5 and remains essentially constant within the entire temperature range.

Fig. 7 The deformation and fracture properties of a superplastic ceramic are quite sensitive to grain size. Examples are given (top) for the monolithic Y-TZP and (bottom) for an $\mathrm{Al}_{2} \mathrm{O}_{3} / \mathrm{Y}$-TZP composite. It is evident from both figures that the flow stress increases, and elongation decreases, as the grain size increases. Strain hardening resulting from grain growth is also apparent at each grain size.

Fig. 8 High resolution lattice image of a grain boundary triple junction in 3Y-YTZ.

Fig. 9 The XPS spectrum from the fracture surface of a Y-TZP specimen, superplastically tested at $1650^{\circ} \mathrm{C}$ at a strain rate of $2.7 \times 10^{-4} \mathrm{~s}^{-1}$, is shown in Fig. 8.

Fig. 10 Flow stress as a function of strain rate for both $\mathrm{Y}-\mathrm{TZP}$ and $\mathrm{Al}_{2} \mathrm{O}_{3} / \mathrm{YTZ}$ at $1550^{\circ} \mathrm{C}$. Except in the high strain rate region, the mechanical strength of the $\mathrm{Al}_{2} \mathrm{O}_{3} / \mathrm{YTZ}$ composite is lower than that of Y-TZP.

Fig. 11 Cavitation behavior in $\mathrm{Y}-\mathrm{TZP}$ and $\mathrm{Al}_{2} \mathrm{O}_{3} / \mathrm{YTZ}$ composite as a function of local true strain.

Fig. 12 Direct comparison of the strengths of Y-TZP and $\mathrm{SiC} / \mathrm{Y}-\mathrm{TZP}$ and $\mathrm{Al}_{2} \mathrm{O}_{3} / \mathrm{Y}-\mathrm{TZP}$ composites at $1550^{\circ} \mathrm{C}$.

Fig. 13 Elongation to failure for a Al 2124 containing 20 vol.\% SiC whisker composite showing HSRS superplasticity in both the longitudinal and transverse directions. 
Fig. 14 Viscosity of Al-6.5wt\%Si alloy and its composites containing 10, 20, and 30 vol.\% SiC particulates (from Moon [16]).

Fig. 15 Strain rate-stress data for the $\mathrm{Al} 2124$ containing 20 vol.\% SiC whisker composite at four different temperatures that bracket the solidus temperature for the matrix.

Fig. 16 Segregation of $\mathrm{Cu}$ and $\mathrm{Mg}$ at a $\mathrm{SiC} / 2 \times x \times \mathrm{Al}$ interface. The melting point of the interfacial region is expected to be reduced as a result of such a segregation. (Ref. 19)

Fig. 17 Elongation-to-failure of ceramic-based materials as a function of temperature-compensated strain rate.(Ref.61) 


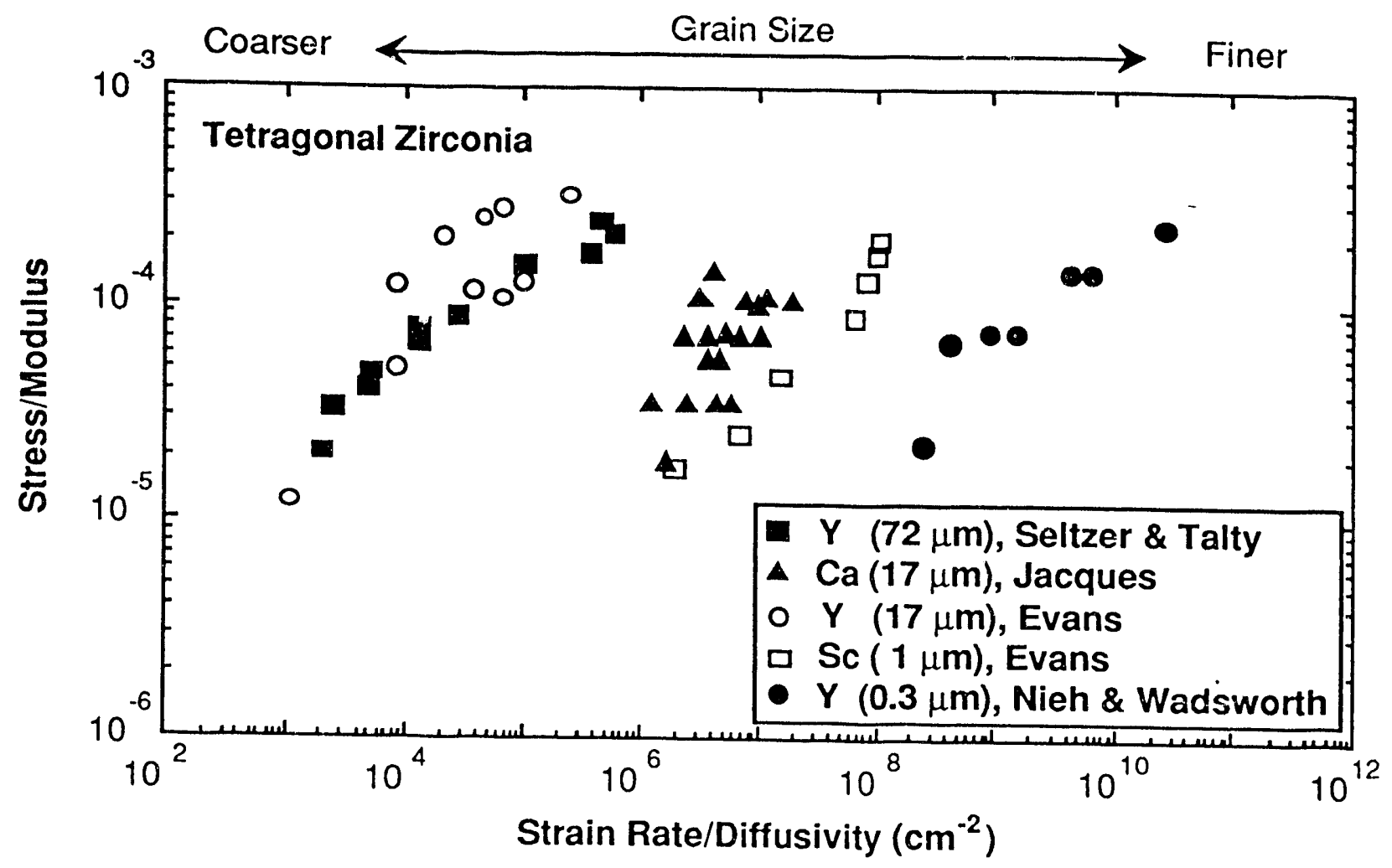

Fig. 1 Modulus-compensated, plastic flow stress as a function of diffusion-compensated, strain rate for tetragonal zirconia. It is evident that flow stress decreases as grain size decreases. 


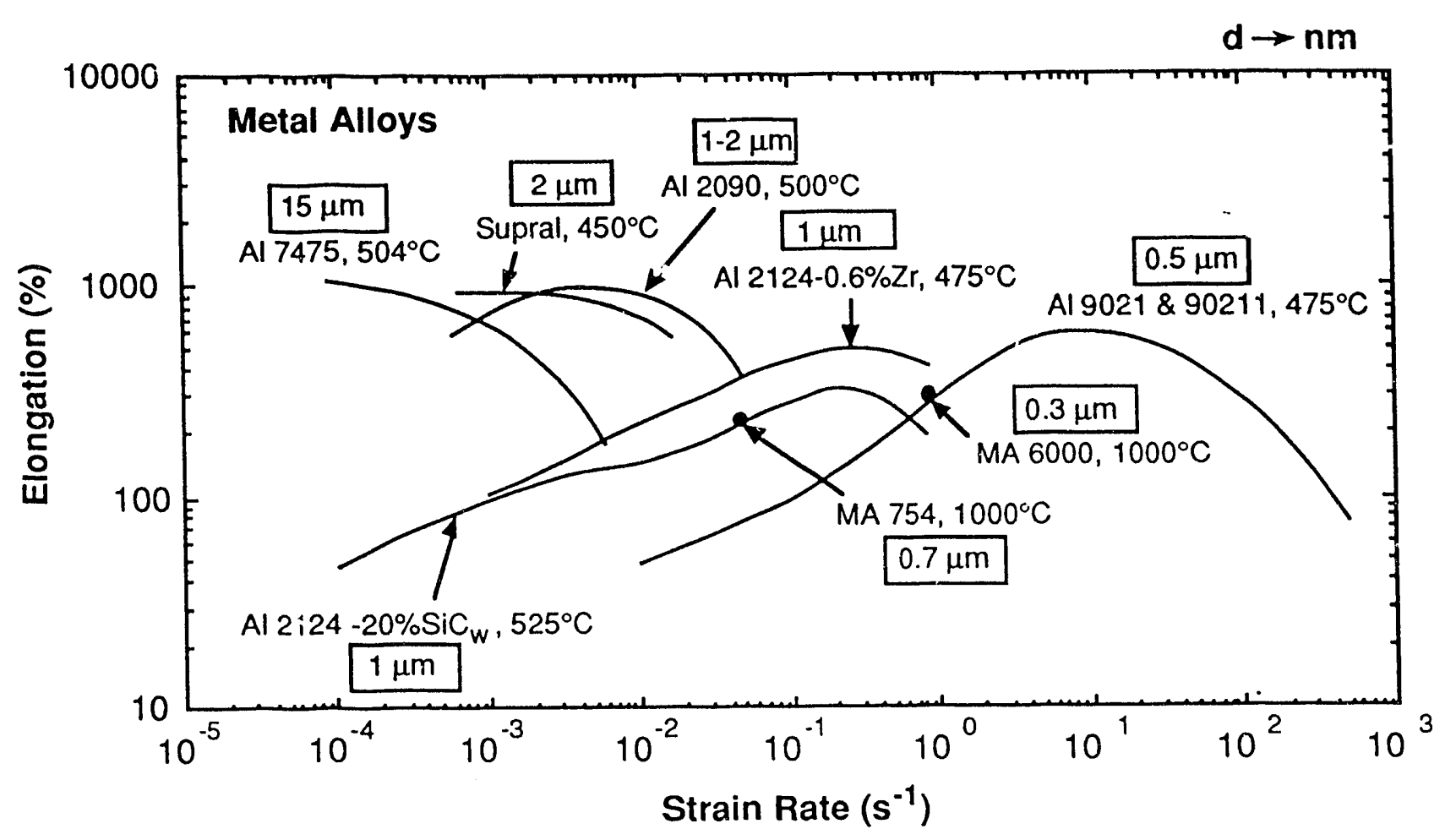

Fig. 2 An overview of the superplastic behavior of metal alloys to demonstrate the grain size effect. 


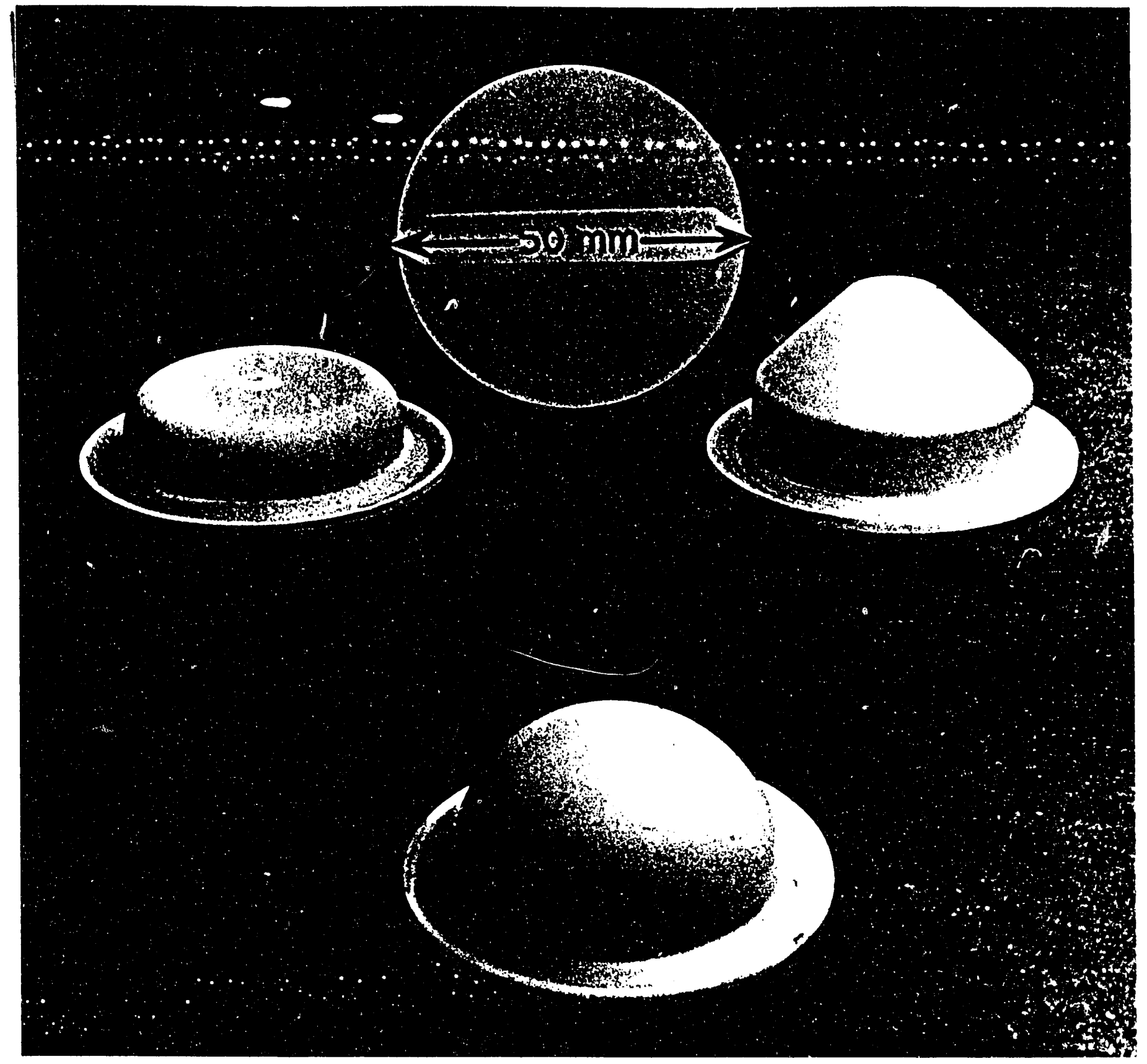

Fig. 3 Examples of superplastically-formed ceramic (Y-TZP) articles including a cone-oncylinder geometry, a hat section, and a hemisphere. 


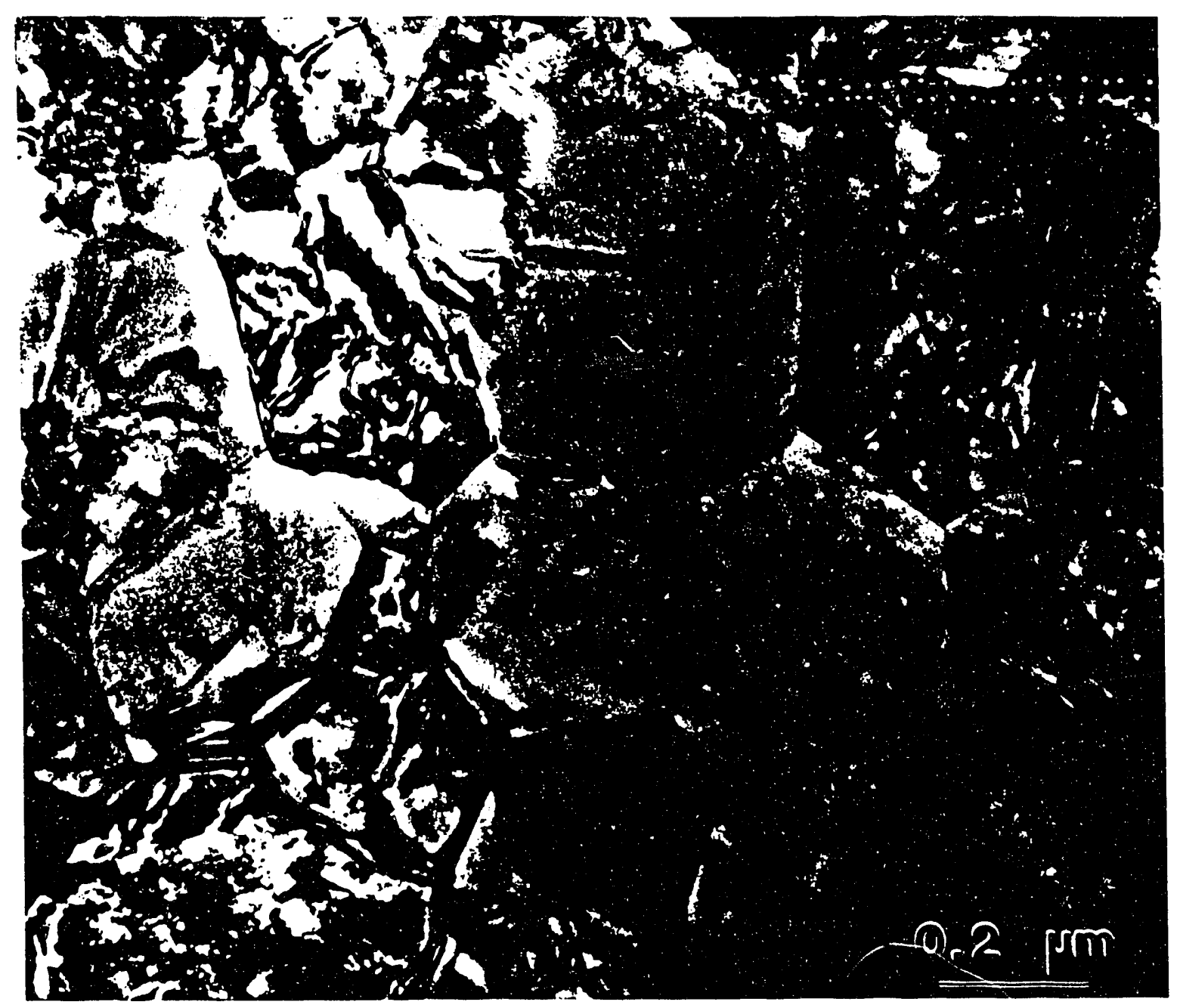

Fig. 4 Transmission electron micrograph of 3Y-YTZ ceramic showing the extremely fine grain size of about $0.2-0.3 \mu \mathrm{m}$. The microstructure consists of equilibrated, hexagonal-shaped grains with sharp apexes. 


\section{SUPERPLASTIC Y-TZP CERAMICS}

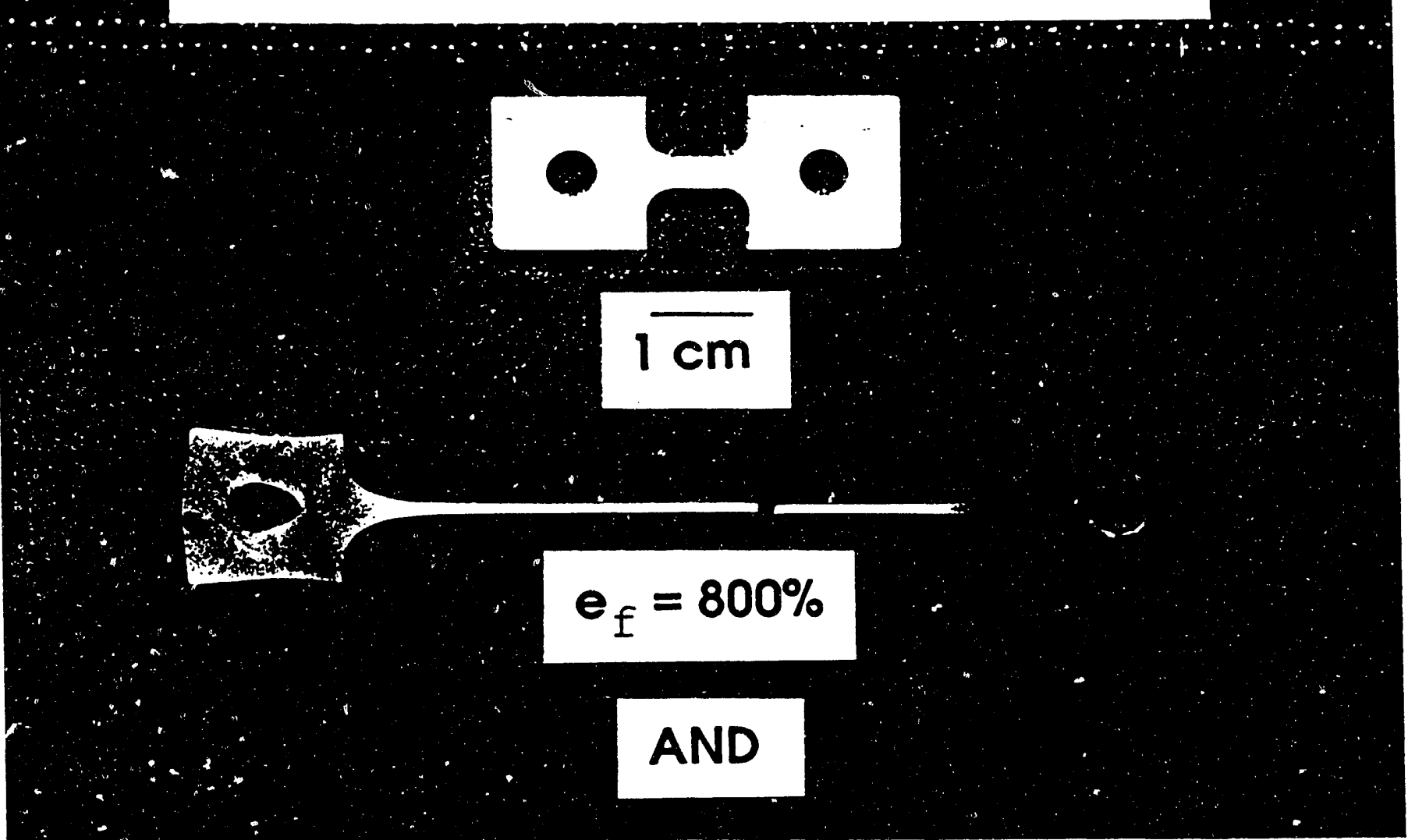

\section{SUPERPLASTIC $20 \% \mathrm{Al}_{2} \mathrm{O}_{3} / \mathrm{Y}$-TZP COMPOSITE}

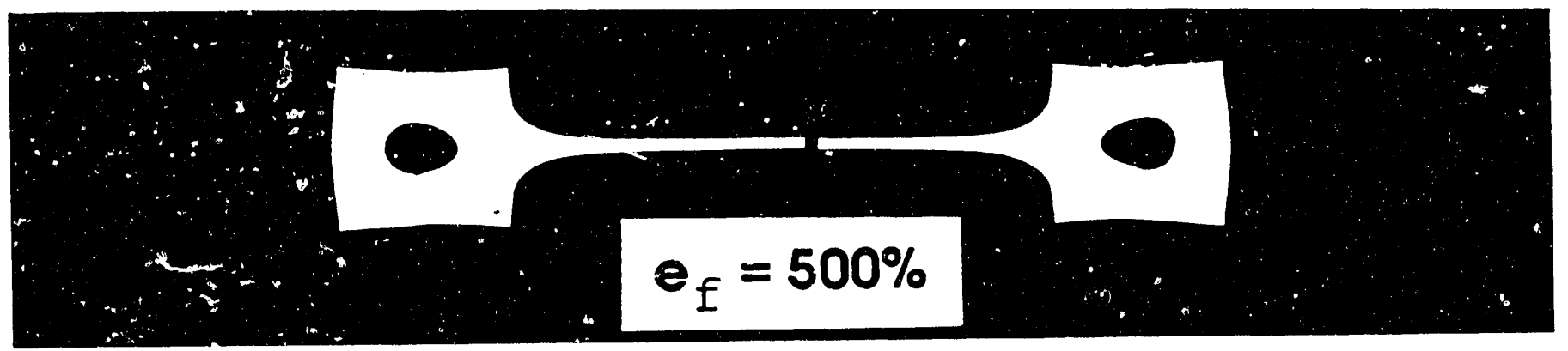

Fig. 5 Comparison of a superplastically deformed Y-TZP sample (800\%) and a superplastically deformed $\mathrm{Al}_{2} \mathrm{O}_{3} / \mathrm{YTZ}$ (625\%) with an undeformed sample. 


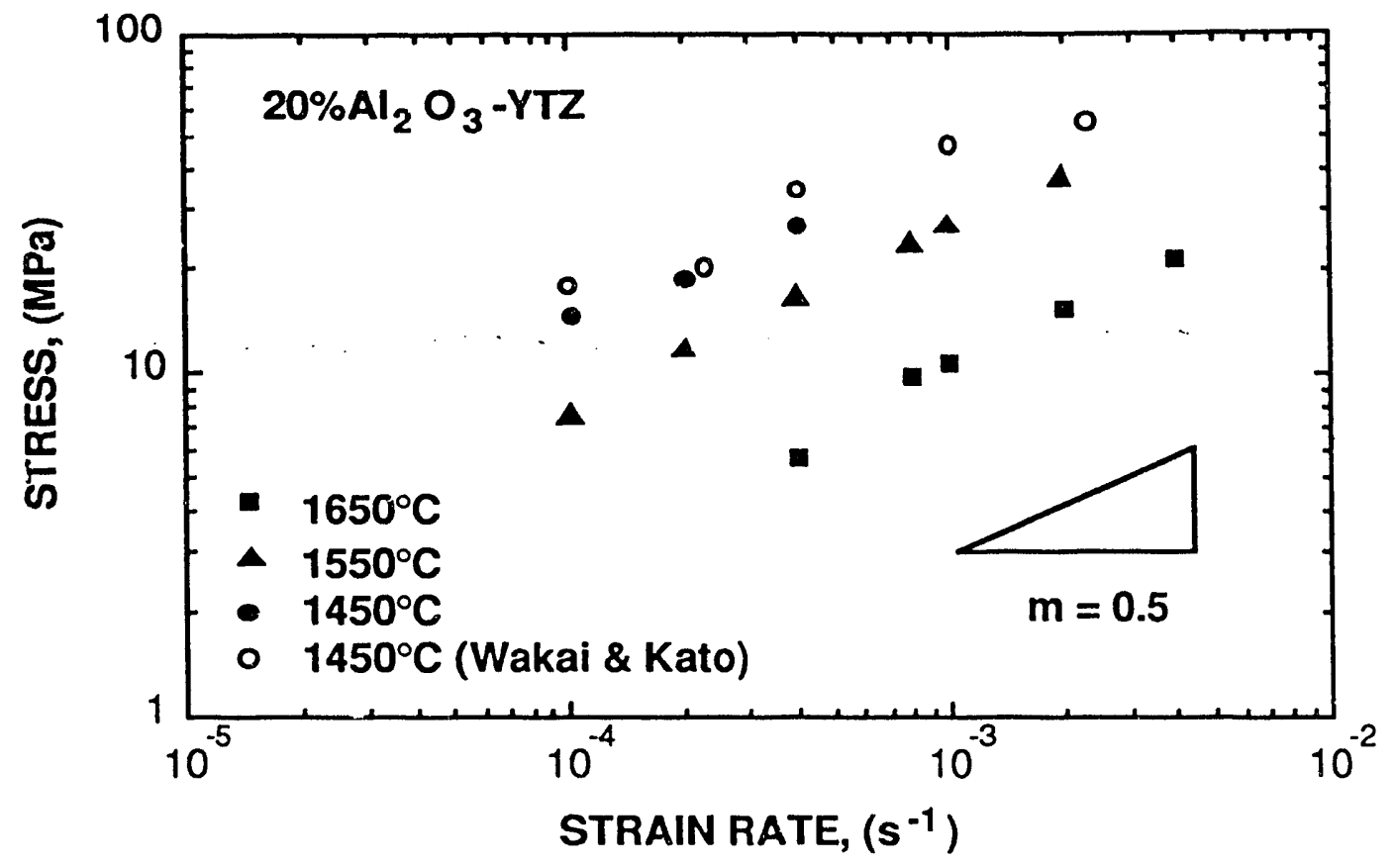

Fig. 6 Stress as a function of strain rate for $\mathrm{Al}_{2} \mathrm{O}_{3} / \mathrm{YTZ}$. The strain rate sensitivity exponent is approximately 0.5 and remains essentially constant within the entire temperature range. 

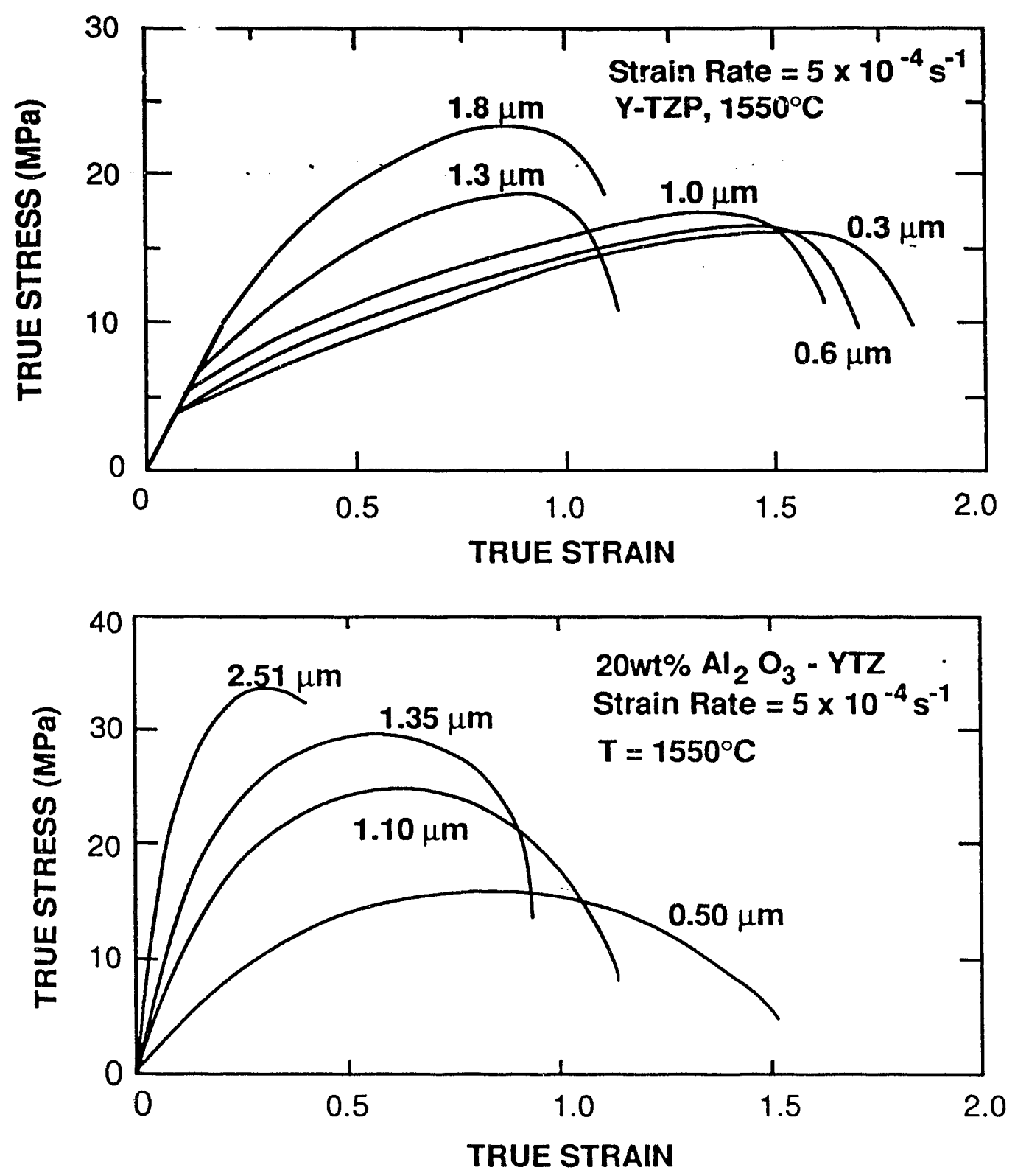

Fig. 7 The deformation and fracture properties of a superplastic ceramic are quite sensitive to grain size. Examples are given (top) for the monolithic Y-TZP and (bottom) for an $\mathrm{Al}_{2} \mathrm{O}_{3} / \mathrm{Y}$-TZP composite. It is evident from both figures that the flow stress inereases, and elongation decreases, as the grain size increases. Strain hardening resultirig from grain growth is also apparent at each grain size. 


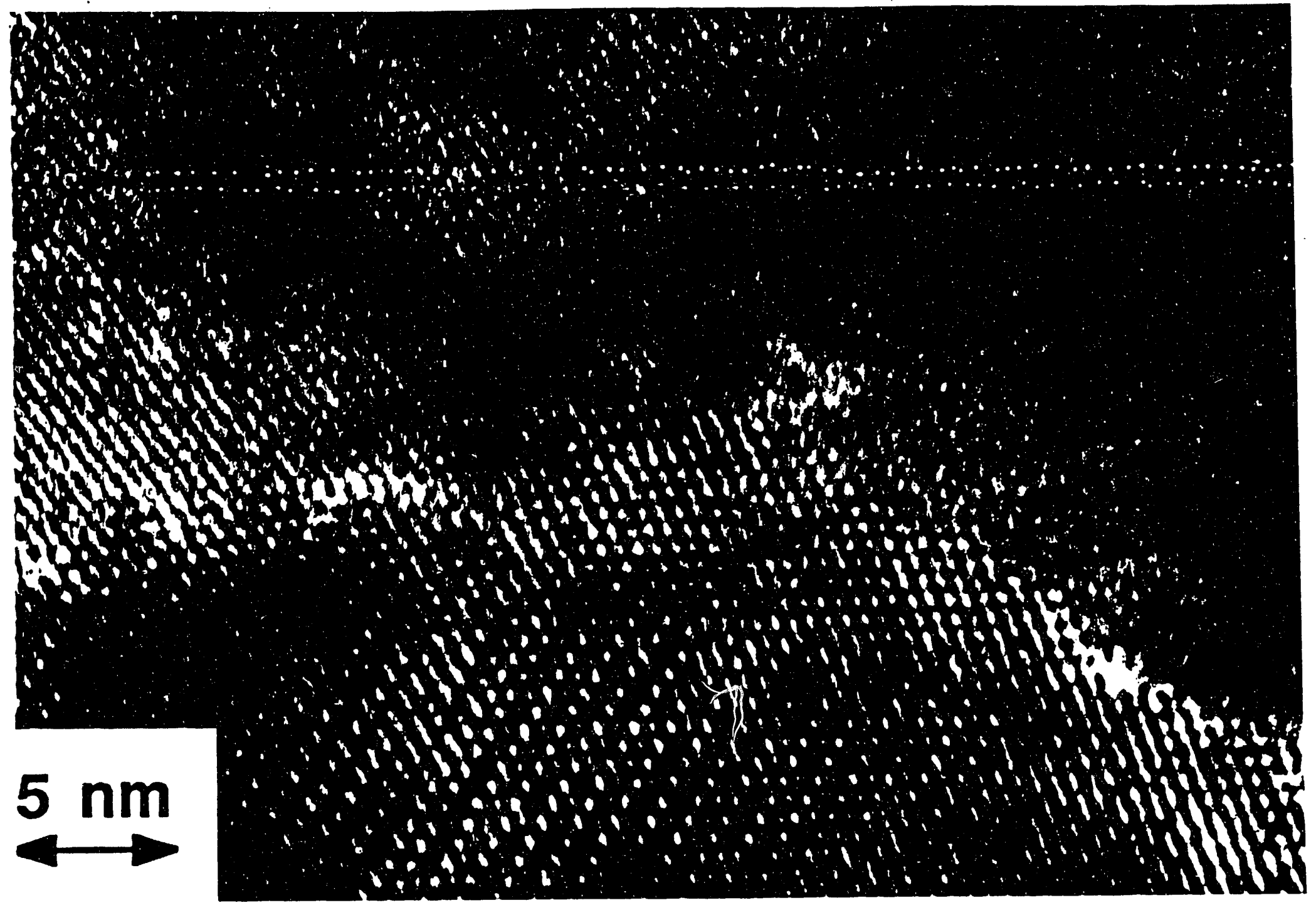

Fig. 8 High resolution lattice image of a grain boundary triple junction in 3Y-YTZ. 


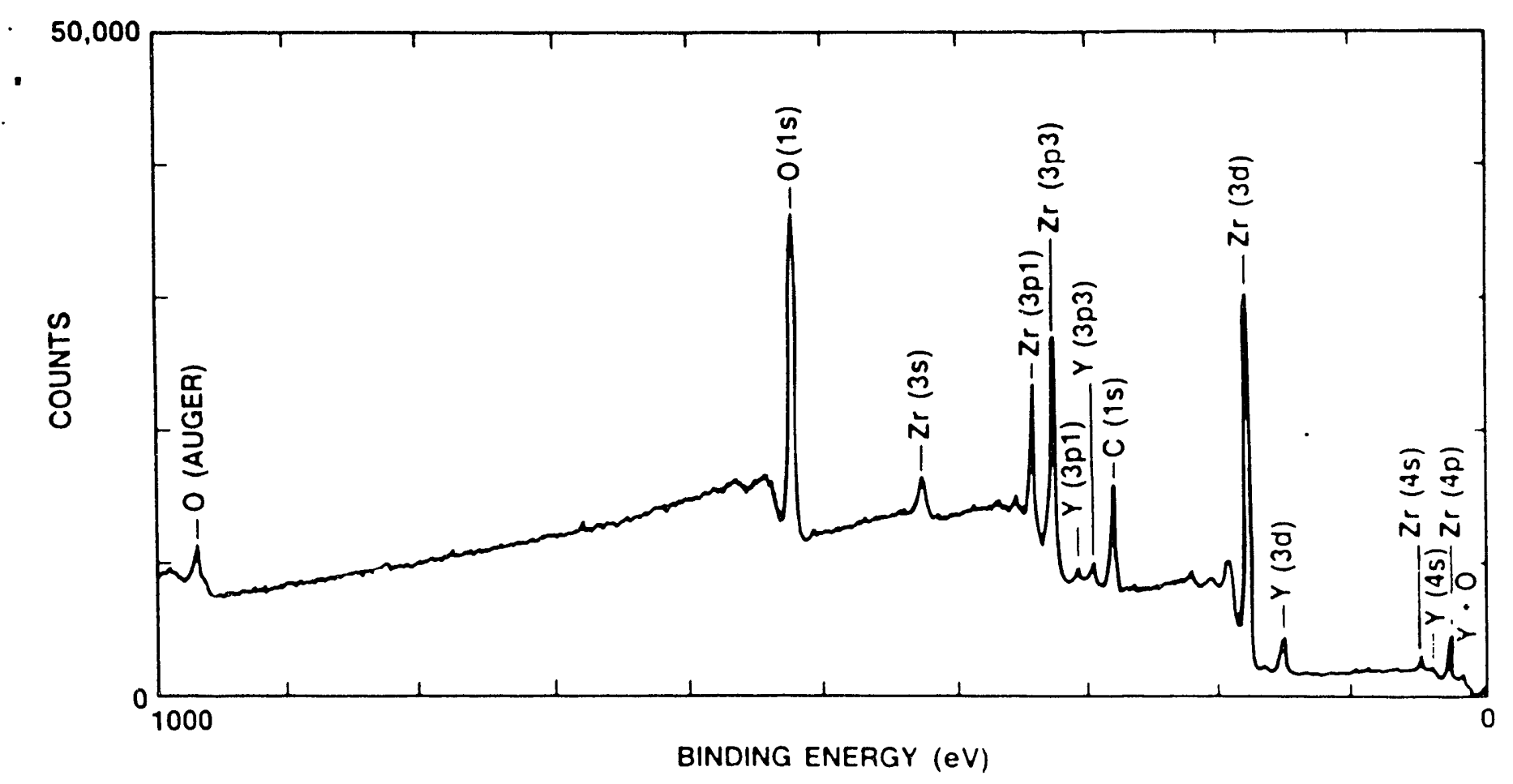

Fig. 9 XPS spectrum from the fracture surface of a Y-TZP specimen, superplastically tested at $1650^{\circ} \mathrm{C}$ at a strain rate of $2.7 \times 10^{-4} \mathrm{~s}^{-1}$. 


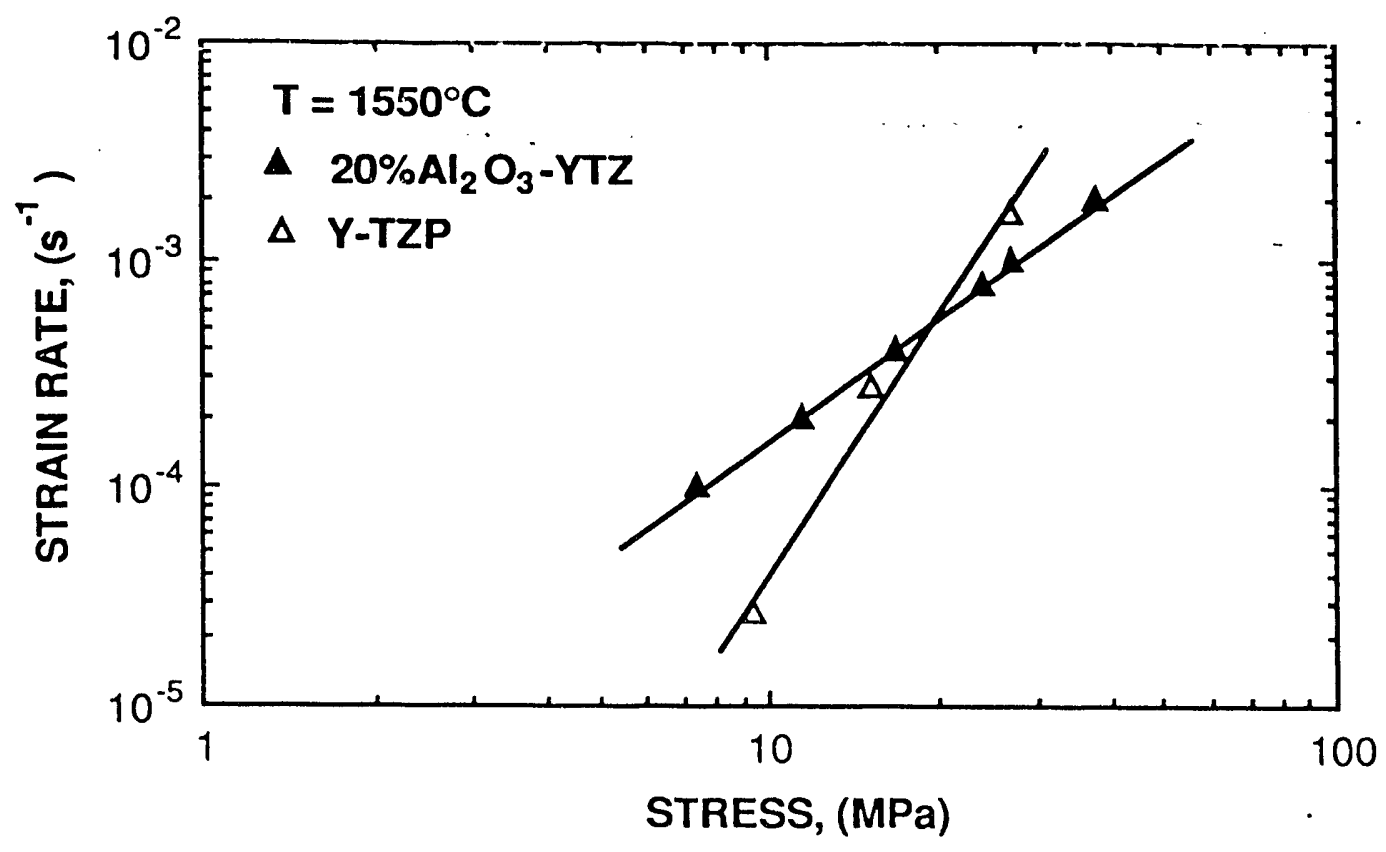

Fig. 10 Flow stress as a function of strain rate for both $\mathrm{Y}-\mathrm{TZP}$ and $\mathrm{Al}_{2} \mathrm{O}_{3} / \mathrm{YTZ}$ at $1550^{\circ} \mathrm{C}$. Except in the high strain rate region, the mechanical strength of the $\mathrm{Al}_{2} \mathrm{O}_{3} / \mathrm{YTZ}$ composite is lower than that of Y-TZP. 


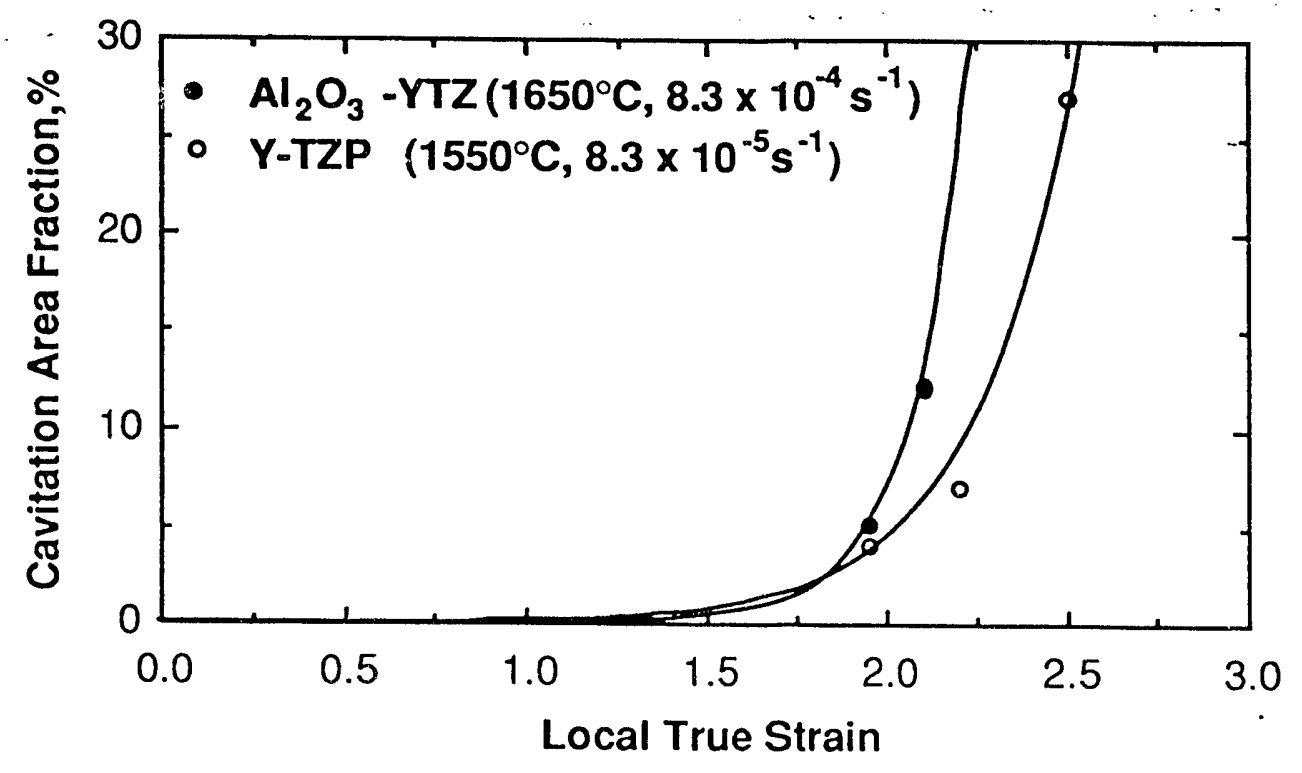

Fig. 11 Cavitation behavior in $\mathrm{Y}-\mathrm{TZP}$ and $\mathrm{Al}_{2} \mathrm{O}_{3} / \mathrm{YTZ}$ composite as a function of local true strain. 


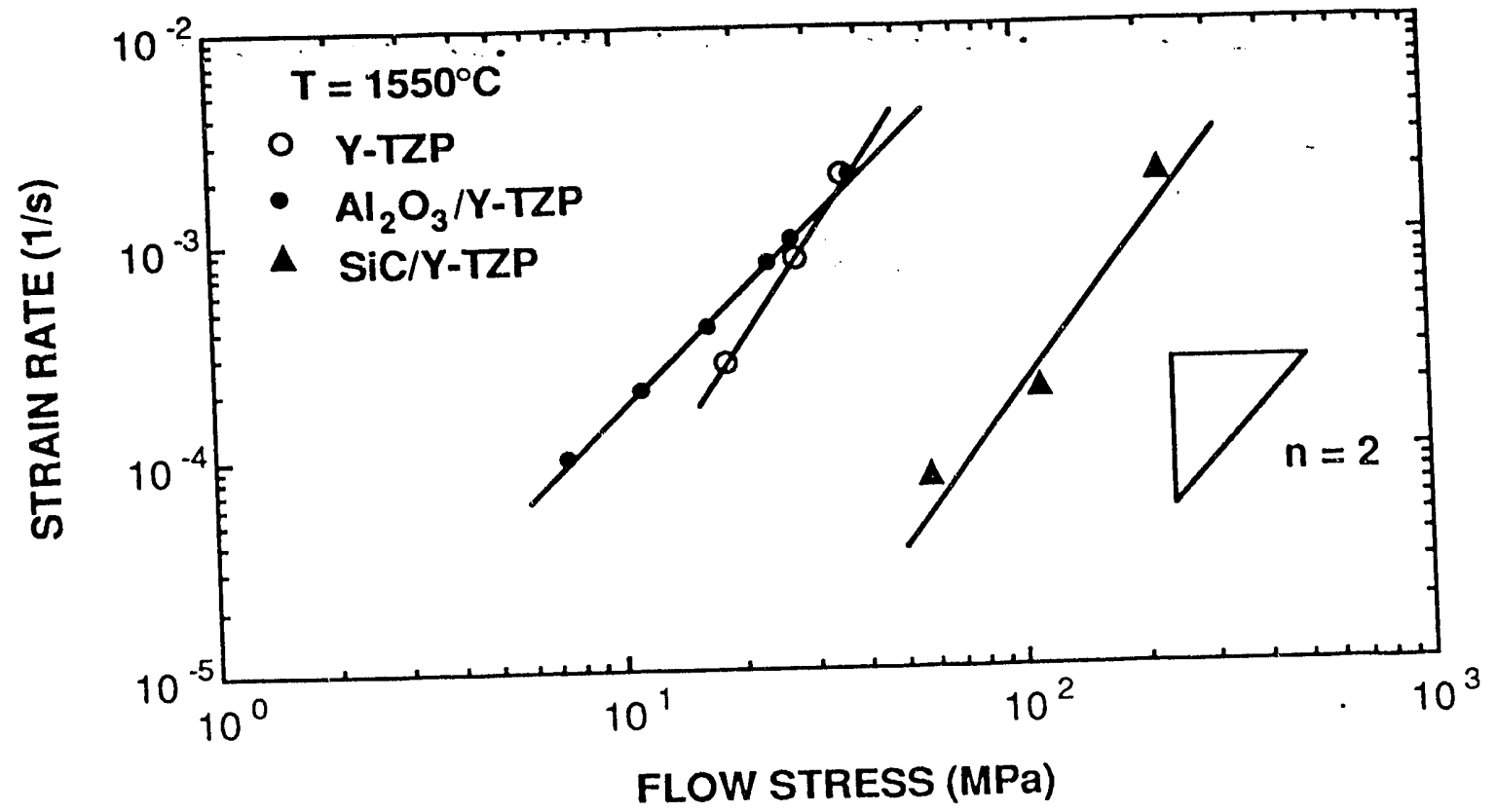

Fig. 12 Direct comparison of the strengths of $\mathrm{Y}-\mathrm{TZP}$ and $\mathrm{SiC} / \mathrm{Y}-\mathrm{TZP}$ and $\mathrm{Al}_{2} \mathrm{O}_{3} / \mathrm{Y}-\mathrm{TZP}$ composites at $1550^{\circ} \mathrm{C}$. 


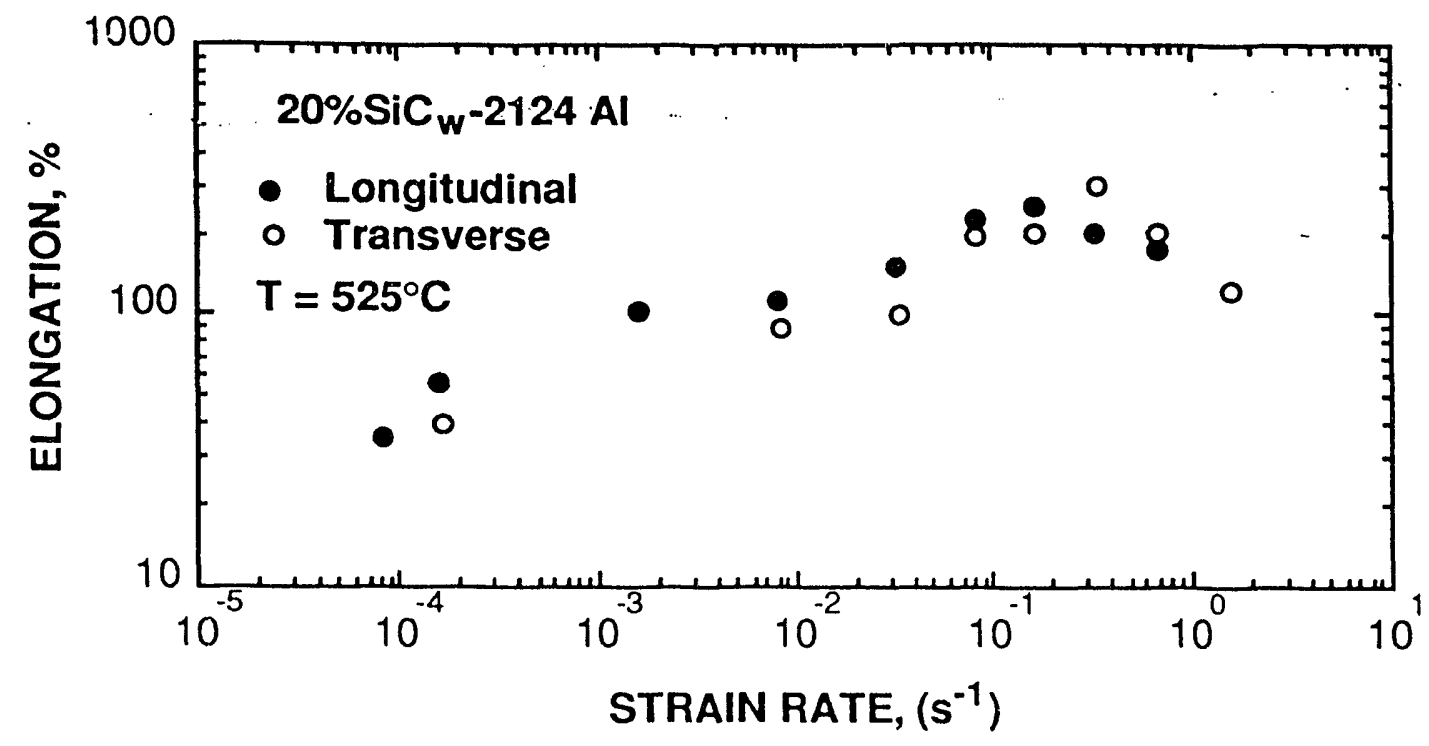

Fig. 13 Elongation to failure for a $\mathrm{Al} 2124$ containing 20 vol.\% SiC whisker composite showing HSRS superplasticity in both the longitudinal and transverse directions. 


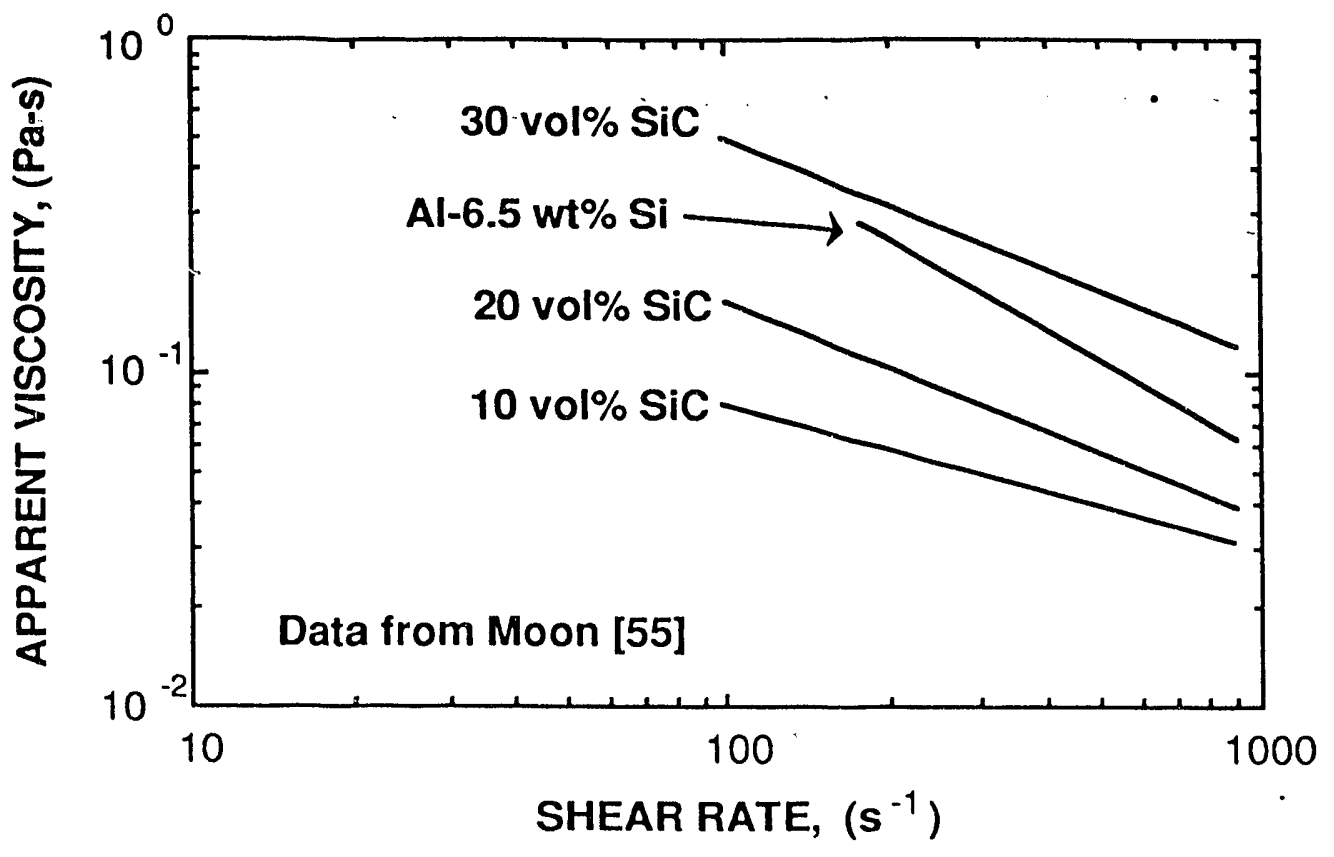

Fig. 14 Viscosity of Al-6.5wt\%Si alloy and its composites containing 10, 20, and 30 vol.\% SiC particulates (from Moon [55]). 


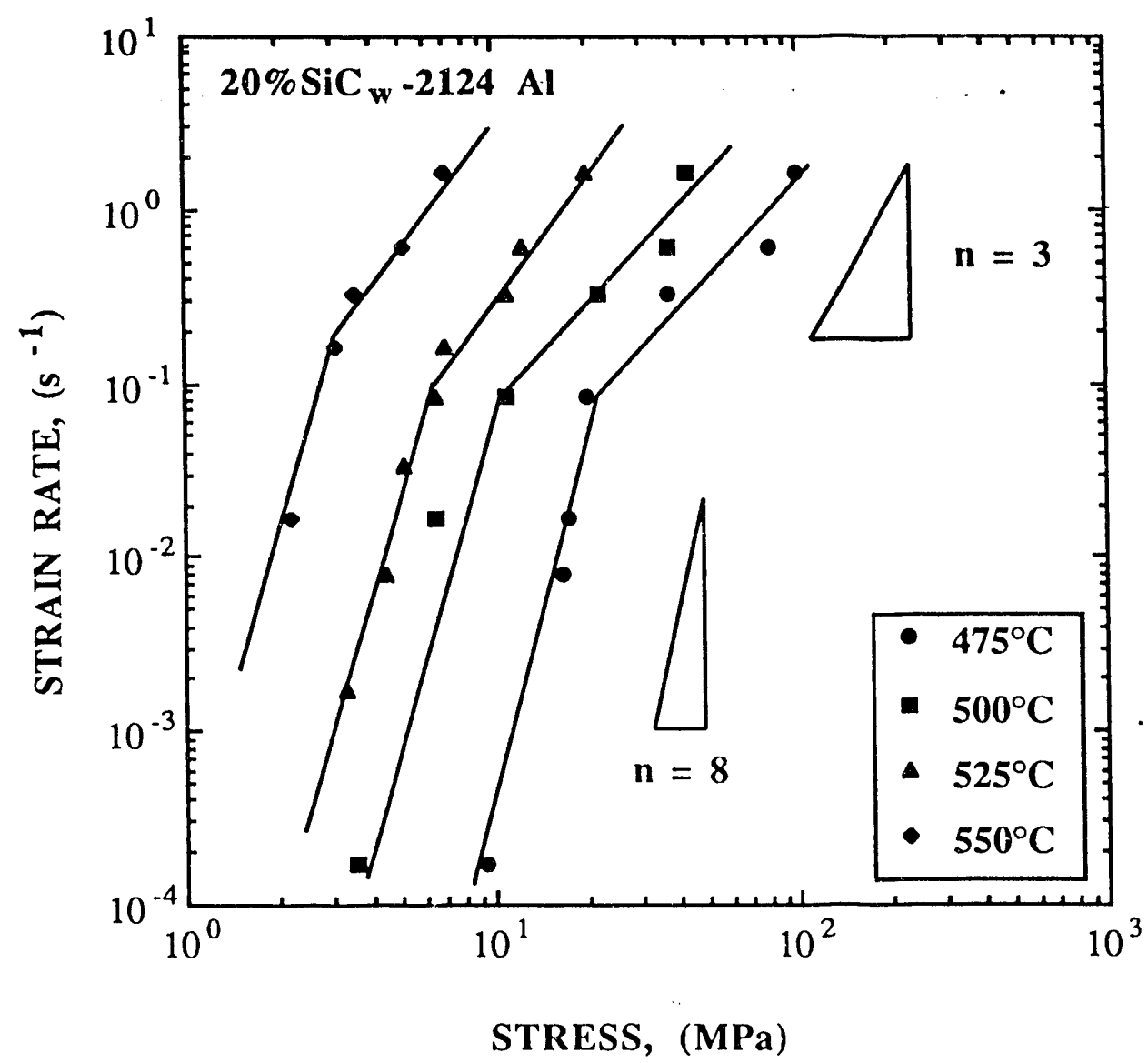

Fig. 15 Strain rate-stress data for the $\mathrm{Al} 2124$ containing 20 vol.\% SiC whisker composite at four different temperatures that bracket the solidus temperature for the matrix. 


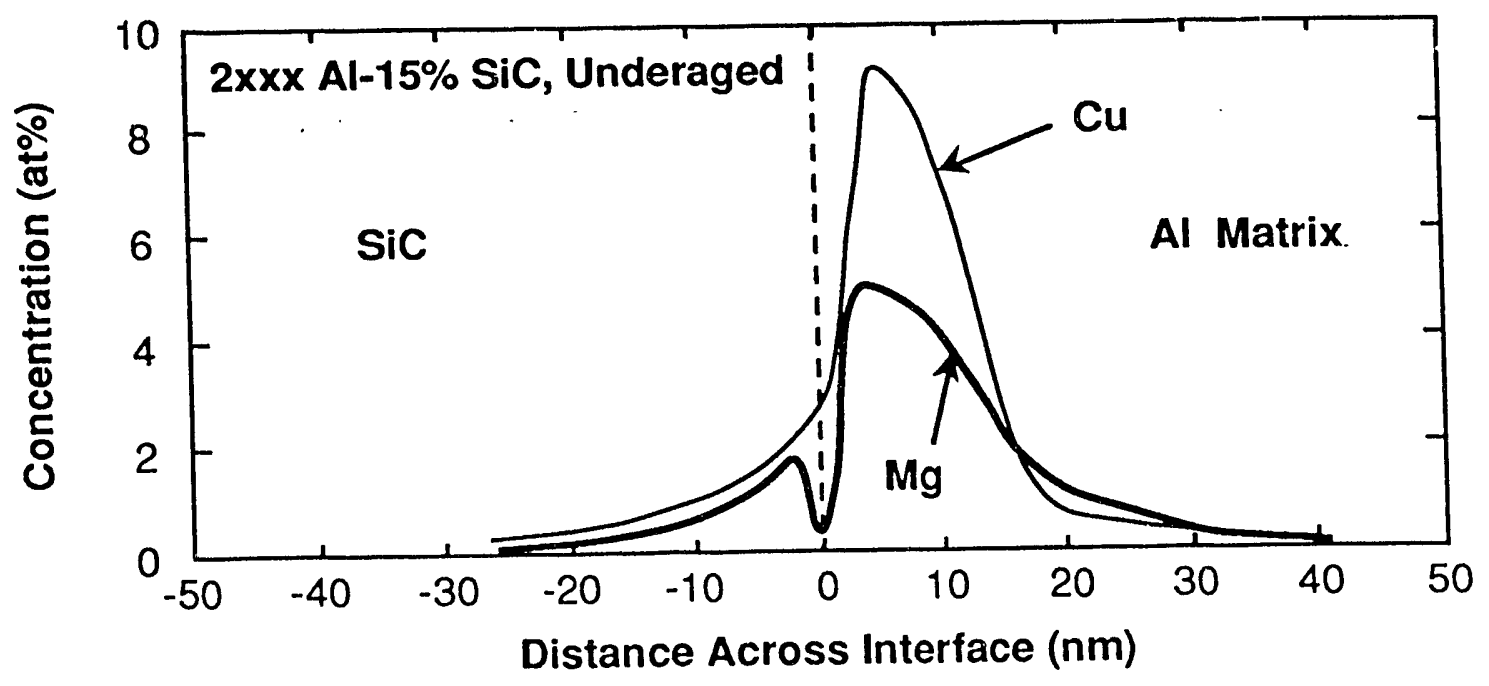

Fig. 16 Segregation of $\mathrm{Cu}$ and $\mathrm{Mg}$ at a SiC/2xxx Al interface. The melting point of the interfacial region is expected to be reduced as a result of such a segregation. (Ref. 58) 


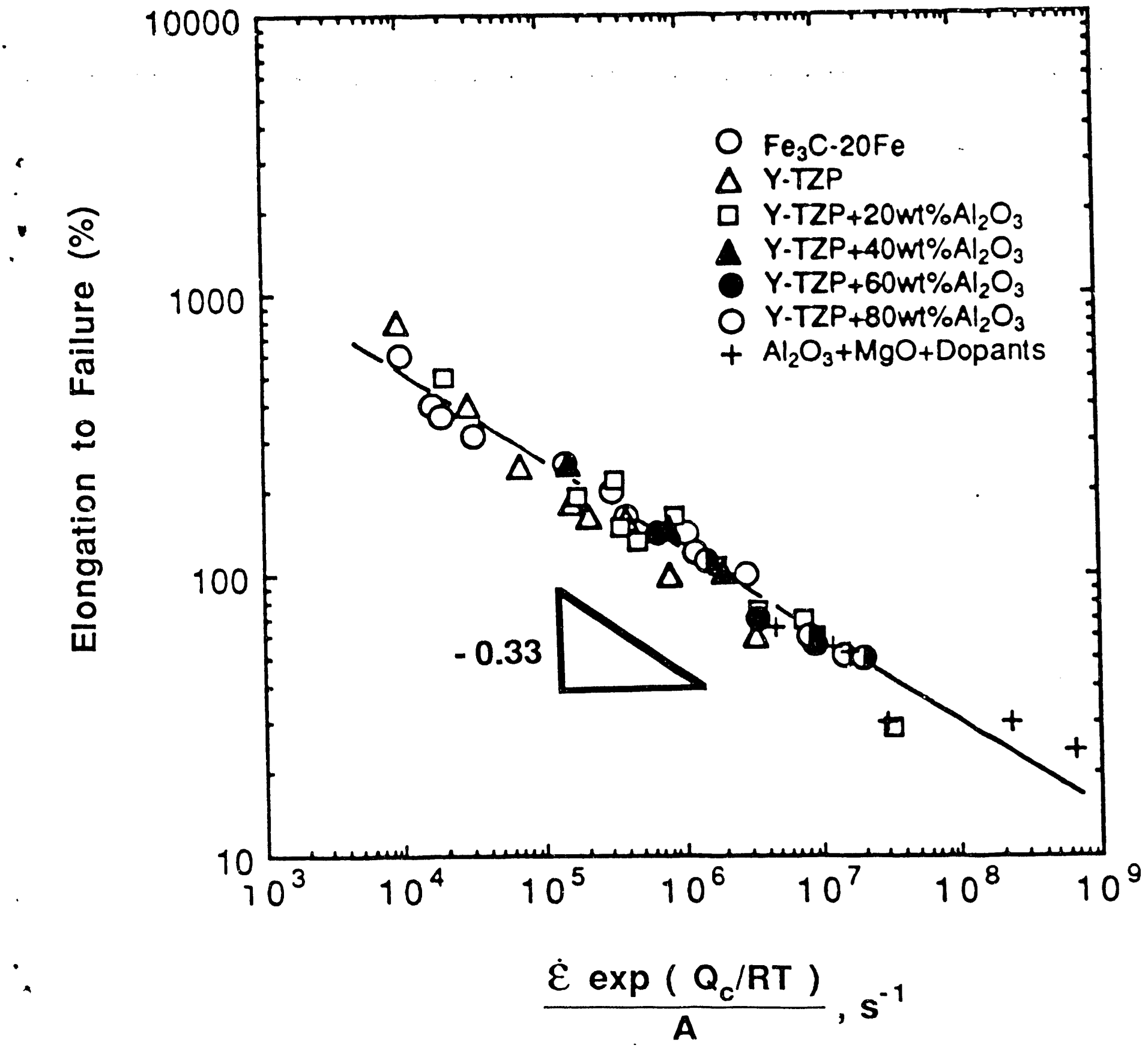

Fig. 17 Elongation-to-failure of ceramic-based materials as a function of temporature-compensated strain rate.(Ref.61) 

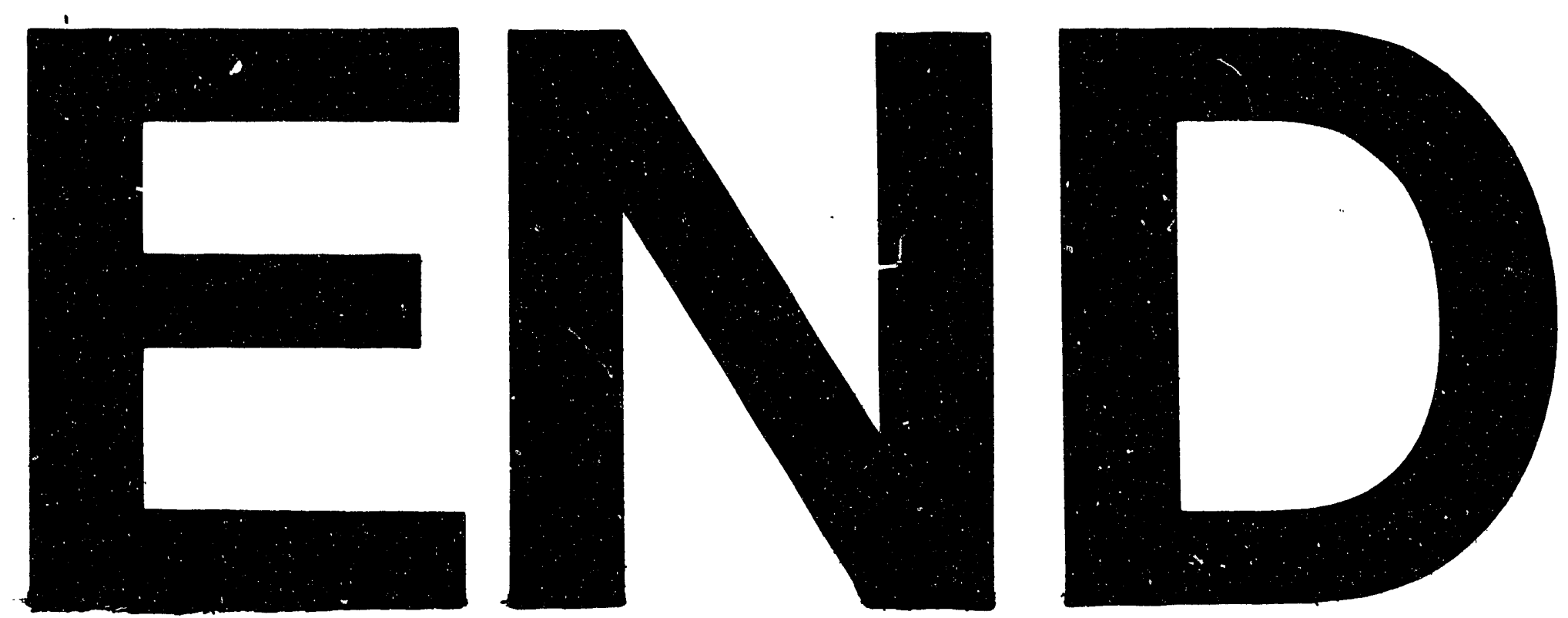

0

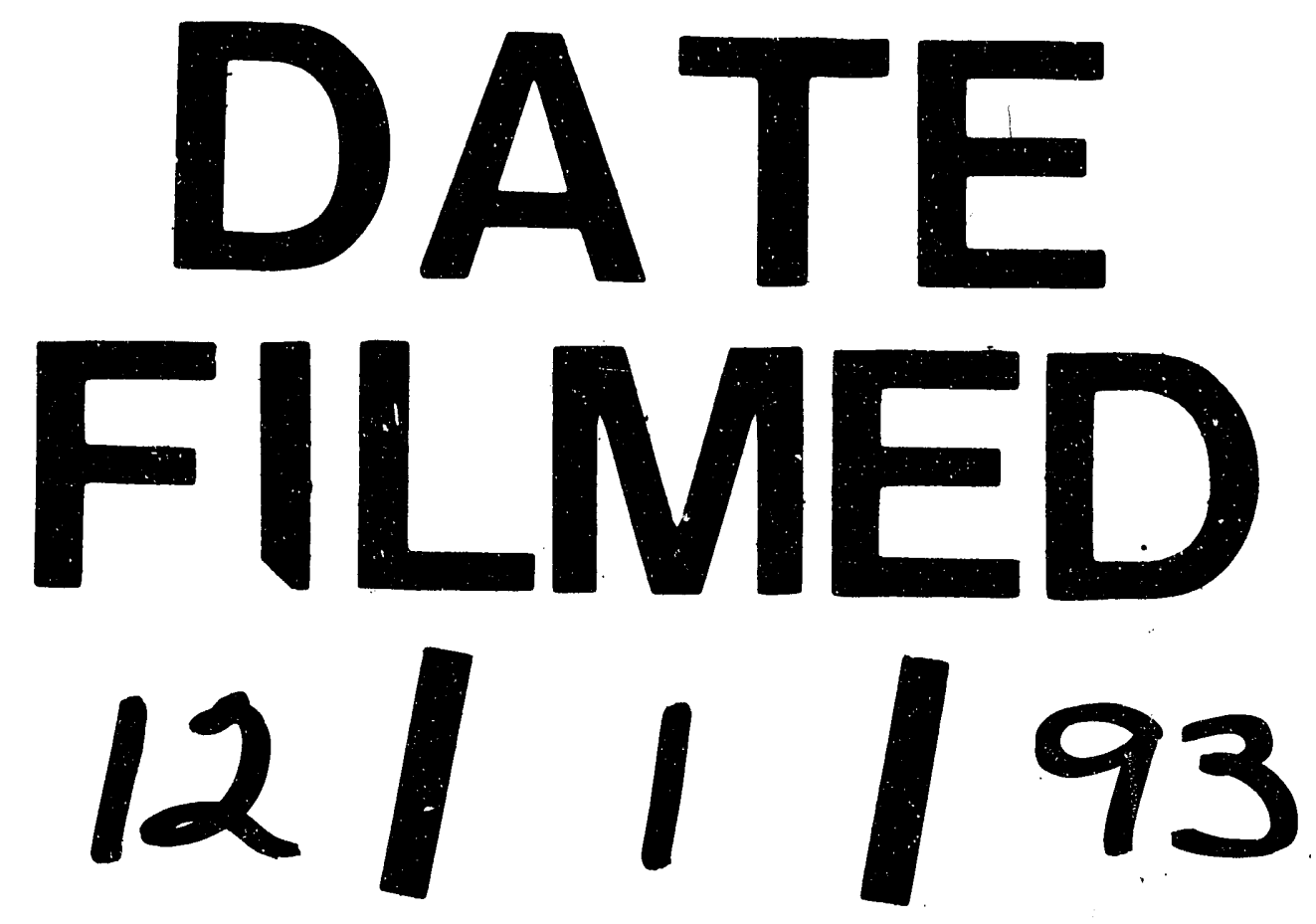

